\title{
31. MAGNETIC DIAGENESIS, ORGANIC INPUT, INTERSTITIAL WATER CHEMISTRY, AND PALEOMAGNETIC RECORD OF THE CARBONATE SEQUENCE ON THE ONTONG JAVA PLATEAU ${ }^{1}$
}

\author{
Robert J. Musgrave, ${ }^{2}$ Margaret L. Delaney, ${ }^{3}$ Rainer Stax,${ }^{4}$ and John A. Tarduno ${ }^{5}$
}

\begin{abstract}
Shipboard paleomagnetic studies on Ocean Drilling Program Leg 130 were plagued by a severe reduction in the remanence intensity, which affected sediments below a sharply defined onset at sub-bottom depths of $50 \mathrm{mbsf}$ or less. This loss of intensity was accompanied by a reduction in magnetic stability and consequent loss of polarity and paleolatitude information. Viscous remanent magnetization and drilling-induced remanences contributed high-coercivity overprints, further obscuring the greatly diminished primary magnetization. The depth at which the reduction in intensity occurred correlates with the organic carbon content of the sediments, and a further relationship is present between intensity downhole and the level of sulfate reduction. This implies that loss of intensity is related to the microbial reduction of magnetite. Reduction of sulfate results in the generation of a magnetic iron sulfide, which appears to be the carrier of the high-coercivity overprints. Oxidation and drying of the sediment after sampling leads to partial destruction of this sulfide, and complete decomposition occurs at temperatures below $300^{\circ} \mathrm{C}$. These features identify the magnetic sulfide as the metastable phase, greigite. Varying inputs of organic material in past times, presumably reflecting both latitude and climatic changes, resulted in varying degrees of reduction, which are now reflected in differences in magnetic intensity, degree of overprinting, and survival of primary magnetization. The highest reduction levels result in the almost total dissolution of magnetite, and the weak surviving remanence is dominated by greigite. At lower reduction states, multidomain magnetite persists together with greigite. Still-less-reducing conditions in turn cause the survival of fine-grained, single-domain magnetite, and then of hematite.

An earlier paleomagnetic study of Ontong Java Plateau sediments from Deep Sea Drilling Project Leg 30 produced a paleolatitude curve that differed significantly from other records of Pacific paleolatitude. It is likely that the samples in this earlier study also carried high-coercivity' overprints, which biased the results. Those samples from Leg 130 that appear to preserve a primary magnetization yielded paleolatitudes consistent with expected Pacific Plate motion.
\end{abstract}

\section{INTRODUCTION}

Paleomagnetic investigations of the carbonate sediment sequence of the Ontong Java Plateau have met with limited success. A study of the paleomagnetic inclination of discrete samples collected from Deep Sea Drilling Project (DSDP) Hole 289 (Hammond et al., 1975) yielded a paleolatitude curve that, although apparently internally consistent, does not match paleomagnetic and hotspot track evidence for absolute motion from other parts of the Pacific Plate (e.g., Duncan, 1981; Sager, 1983; Sager and Pringle, 1988). Cryogenic magnetometer long-core measurements on Ocean Drilling Program (ODP) Leg 130 were frustrated by an almost complete loss of signal following a precipitous drop in the remanence intensity of 2 orders of magnitude below a critical depth of between 10 and 50 meters below seafloor (mbsf). Although some intervals of consistently preserved magnetostratigraphy were observed in the Oligocene section of Hole 803D and the Miocene to Eocene of Site 807, the signal overall was both discontinuous and biased toward one polarity. Similarly, inclinations of the Tertiary sediment samples in the earlier DSDP study appeared to be biased (13 of a total of 18 samples have a positive inclination). Inclination flattening during sediment compaction (Anson and Kodama, 1987; Arason and Levi, 1990; Deamer and Kodama, 1990; Levi and Baner-

\footnotetext{
'Berger, W.H., Kroenke, L.W., Mayer, L.A., et al., 1993. Proc. ODP, Sci. Results, 130: College Station, TX (Ocean Drilling Program).

${ }^{2}$ Geology Department, University of Tasmania, G.P.O. Box 252C, Hobart, Tasmania 7001, Australia (present address: Ocean Drilling Program, Texas A\&M University, 1000 Discovery Drive, College Station, TX 77845-9547, U.S.A.).

${ }^{3}$ Institute of Marine Sciences, University of California, Santa Cruz, Applied Sciences Building, 1156 High Street, Santa Cruz, CA 95064, U.S.A.

${ }^{4}$ Alfred Wegener Institute for Polar and Marine Research, Columbusstrasse, D-2850 Bremerhaven, Federal Republic of Germany.

${ }^{5}$ Geological Research Division, Scripps Institution of Oceanography, University of California, San Diego, La Jolla, CA 92093 , U.S.A.
}

jee, 1990; Tarduno, 1990), a mechanism suggested as the explanation of other anomalous paleolatitude records from marine sediments, cannot explain this bias in the polarity distribution. An alternate explanation is that the alternating field (AF) demagnetization conducted in the two studies (to a maximum of $30 \mathrm{mT}$ in the DSDP study, with characteristic inclinations determined at $10 \mathrm{mT}$, and to a maximum of $15 \mathrm{mT}$ on board Leg 130) was unable to completely remove an overprint.

During Leg 130, a correlation was noted between the sulfate ion concentration in the interstitial water and remanence intensity over the interval in which remanence suddenly declines and the magnetostratigraphic signal is lost (the intensity reduction event [IRE]). This relationship was interpreted as the result of a link between microbial reduction of the sediments, destruction of magnetite, and production of magnetic iron sulfides. A general correlation between the sub-bottom depth at which these diagenetic processes occurred and the local organic productivity was suspected, but low total organic carbon (TOC) contents precluded shipboard evaluation of this relationship. Microbially driven reduction of magnetite has been reported by several authors (e.g., Karlin and Levi, 1983; van Vreumingen, 1984; Bloemendal et al., 1989). Sager (1988) suspected that a metastable magnetic iron sulfide, either greigite or pyrrhotite, had been generated in Leg 101 sediments, and that this phase was the carrier of an overprint.

Land-based paleomagnetic studies of discrete carbonate samples from Leg 130 have focused on recognition of the magnetic mineralogy of the sediments, with the intention both to understand the magnetic diagenesis and to reveal the depositional and early postdepositional remanence (DRM and $\mathrm{pDRM}$ ) for magneto-stratigraphic and paleolatitude purposes. Direct observation of the magnetic mineralogy was not possible, as the very low concentrations of magnetic phases, implied by typical remanences of $<10^{-5}$ $\mathrm{Am}^{-1}$ that are encountered below the IRE, prevented separation of 
significant quantities and analysis of these phases. Magnetic methods of determining the magnetic mineralogy proved to be more amenable, though indirect.

\section{METHODS}

A $2 \mathrm{G}$ pass-through cryogenic magnetometer (PCM) with on-axis AF demagnetization coils was available for use during Leg 130. Analysis with this instrument was principally directed toward recognition of the magnetic polarity sequence. Record-breaking core recovery coupled with low intensities of magnetization through most of the carbonate sequence limited our ability to conduct useful PCM measurements on a large proportion of the cores, and so detailed shipboard analysis, including measurement at 3 - and 5-cm intervals (and 1-cm intervals in the top one or two cores of each hole), and AF demagnetization at 5,10 , and $15 \mathrm{mT}$, was discontinued a few cores below the IRE in each hole. Below the IRE, measurement of carbonate cores was expanded to $10-\mathrm{cm}$ intervals, and demagnetization was conducted as a single step at $15 \mathrm{mT}$. In cores where intensities dropped below $10^{-4} \mathrm{Am}^{-1}$, no systematic magnetization was observed, and demagnetization was restricted to one section per core, which was scanned for evidence of reliably measurable remanence. Measurement was discontinued below the IRE in Holes 805C, 806C, and $807 \mathrm{~B}$, stopping at the tenth core in each.

Discrete samples were collected with the intention of determining primary magnetic inclinations, from which paleolatitudes could be directly calculated. These samples were reserved for study on land, with a more sensitive cryogenic magnetometer than was available aboard ship. Two samples were usually sampled from each core in the longest Tertiary-Quaternary sequence possible at each site, either from a single hole per site (Holes 803D, 804C, and 806B) or by continuing sampling from the base of one hole to the equivalent sub-bottom depth in a second, deeper hole (from Hole $805 \mathrm{~B}$ to $805 \mathrm{C}$, and from Hole $807 \mathrm{~A}$ to $807 \mathrm{C}$ ). Discrete samples were taken by pressing standard ODP plastic boxes $(2.1 \times 2.1 \times 1.5 \mathrm{~cm})$ into soft carbonate oozes. Stiffer oozes were cut with a stainless steel knife, and soft chalks with parallel saw blades, and these samples were also placed into ODP boxes. More consolidated chalks and limestones were sampled as cylinders cut with the $2.5-\mathrm{cm}$ diameter minidrill apparatus. Samples in the oozes were taken only from parts of the core that displayed no evidence of "flow-in" or other sampling disruption. Where chalks and limestones had been biscuited, samples were taken in segments long enough to allow confidence that the segment had not been rotated about a horizontal axis. Measurement of the discrete samples was reserved for land-based study, where more sensitive magnetometers and better shielding from spurious fields is available.

On-land paleomagnetic and rock magnetic studies of the discrete carbonate samples were conducted at the Bureau of Mineral ResourcesAustralian National University facility at Black Mountain, Canberra. Remanence was measured on an SCT two-axis cryogenic magnetometer. Systematic and repeatable measurements of remanences as small as $5 \times 10^{-6} \mathrm{Am}^{-1}$ on the $6.6-\mathrm{cm}^{3}$ box samples were achieved. $\mathrm{AF}$ demagnetization in 5-mT steps to $50 \mathrm{mT}$ (or until the inconsistency between repeated measurements of the samples in first upright and then inverted orientations exceeded $25^{\circ}$ ) was applied to plasticboxed samples from Sites 803 to 806 . A Schonstedt two-axis, tumblershielded AF demagnetizer was used. Stepwise thermal demagnetization was conducted on cylinder samples from Sites $803,805,806$, and 807 to a maximum of $625^{\circ} \mathrm{C}$, using two feedback-controlled, Helmholtzcoil-shielded furnaces. AF demagnetization is usually preferred for plastic-boxed samples, as this technique does not require the samples to be removed from their boxes or dried. However, the failure to completely remove magnetic overprints from the primary magnetization by $\mathrm{AF}$ demagnetization in many of the boxed samples, and the comparatively good resolution of the primary magnetization by thermal demagnetization of the cylinders, encouraged an attempt to apply thermal demagnetization to boxed samples from Hole 807A. These were slowly dried while still in their boxes, and (where possible) removed from the boxes whole. Samples that could be successfully removed were heated in a Schonstedt shielded thermal demagnetizer in steps up to $575^{\circ} \mathrm{C}$. After cooling, samples were returned (maintaining their orientation) to the boxes for measurement. The boxes were themselves AF demagnetized to minimize their contribution to the measured remanence. Demagnetization remanences were plotted on cartesian ("As-Zijderveld") plots (Zijderveld, 1967), following the modification suggested by Roy and Park (1974). Components of magnetization were fitted by principal component analysis of linear segments of the demagnetization path (Kirschvink, 1980).

An isothermal remanence (IRM) was imparted to selected samples by a steady-field electromagnet in steps of $0.1 \mathrm{~T}$ from $0.2 \mathrm{~T}$ up to saturation or until the limits of the DC power supply at applied fields of about 1.5 to $1.7 \mathrm{~T}$.

An attempt was made to concentrate the magnetic fraction from groups of samples representing various intervals in the carbonate sequence by magnetic separation after removal of the carbonate fraction by dissolution in $10 \% \mathrm{HCl}$. The concentrations of the magnetic fraction proved too low for this to be successful.

Interstitial water sampling was conducted on 5- to 10-cm-long, whole-round sections cut immediately after the cores arrived on deck. Before squeezing, whole-round surfaces were carefully scraped with spatulas to remove potentially contaminated exteriors. The wholeround sections were then placed into stainless-steel squeezing devices (Mannheim and Sayles, 1974) and squeezed with a hydraulic press. Interstitial water samples were filtered through $0.45-\mu \mathrm{m}$ disposable filters and collected in plastic syringes. Among other measurements, sulfate concentrations were determined by ion chromatography with a Dionex 2120i chromatograph.

The initial failure of the nitrogen-carbon-sulfur (NCS) analyzer restricted determinations of TOC at Sites 803,804 , and 805 to use of the Rock-Eval pyrolysis technique (Espitalié et al., 1977). The TOC values at these sites were mostly less than the $0.05 \%$ detection limit of this technique. At Sites 806 and 807 , the NCS analyzer was available to determine total carbon (TC), and TOC was then calculated as the difference between TC and inorganic carbon. Calculated TOC values were very low, between $0.02 \%$ and $0.6 \%$, near the detection limit of the shipboard analytical techniques. Because of a relationship suspected between diagenesis of the magnetic phases and organic content of the upper few tens of meters of the cores, TOC was redetermined on land for samples from Cores $1 \mathrm{H}$ to $6 \mathrm{H}$ of Holes $803 \mathrm{D}$, $804 \mathrm{C}, 805 \mathrm{C}, 806 \mathrm{~B}$, and $807 \mathrm{~A}$. Measurements were made with a Heraeus carbon-hydrogen-nitrogen $(\mathrm{CHN})$ analyzer on a bulk sample (TC) and on a HCl-treated split of the same sample (TOC'). TOC was calculated by:

\section{TOC $=[100-(8.334 \times$ TC $)] /\left[\left(100 /\right.\right.$ TOC $\left.\left.^{\prime}\right)-8.334\right]$. \\ RESULTS \\ Pass-through Cryogenic Magnetometer}

Despite some ambiguities in magnetic polarity caused by problems with the multishot orientation tool, and compounded by the low paleomagnetic inclination resulting from the near-equatorial latitude of Leg 130 sites, a clearly defined magnetostratigraphy can be determined from demagnetized PCM measurements of the uppermost part of each site (Fig. 1). This otherwise clear signal is totally lost, however, below a point where a sharply defined drop of about 2 orders of magnitude occurs in the intensity (the IRE). Above the IRE, maximum intensities after $15-\mathrm{mT}$ AF demagnetization range from about $10^{-2}$ $\mathrm{Am}^{-1}$ at Site 806 to about $2 \times 10^{-3} \mathrm{Am}^{-1}$ at Site 803 . Immediately below the IRE at all sites, maximum demagnetized intensities drop to values of about $10^{-4}$ to $10^{-5} \mathrm{Am}^{-1}$ (roughly the detection limit of the PCM). Sub-bottom depths of the IRE vary from a maximum of $47.5 \mathrm{mbsf}$ in Hole $803 \mathrm{C}$ to a minimum of $9.8 \mathrm{mbsf}$ in Hole $806 \mathrm{C}$. Differences in both the sub-bottom depth of the IRE and in sedimentation rates 
Inclination

Intensity
$(\mathrm{mA} / \mathrm{m})$

B

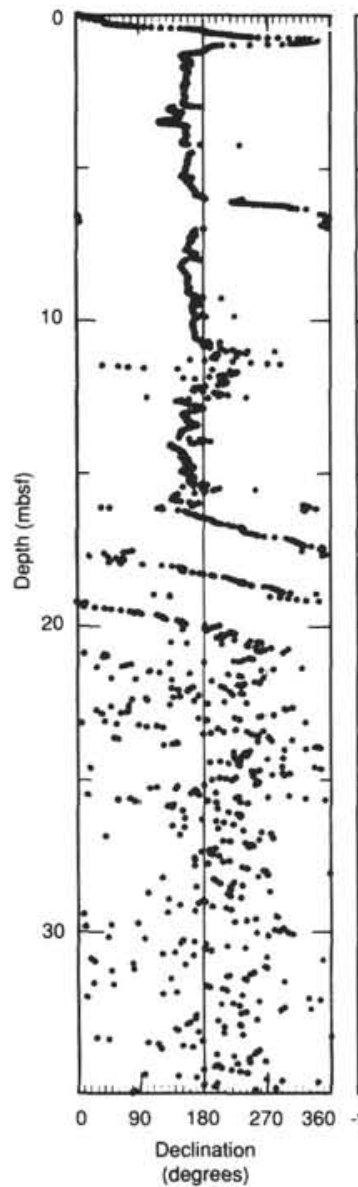

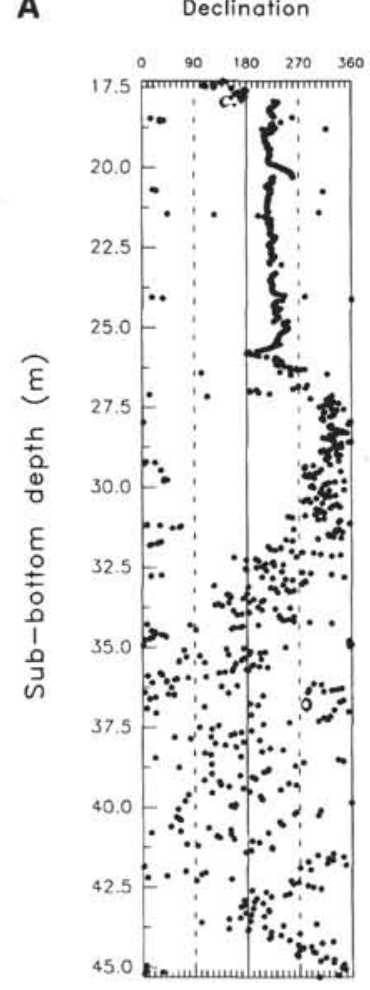

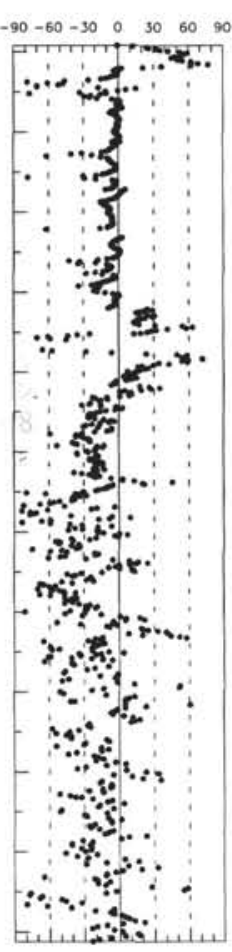

C
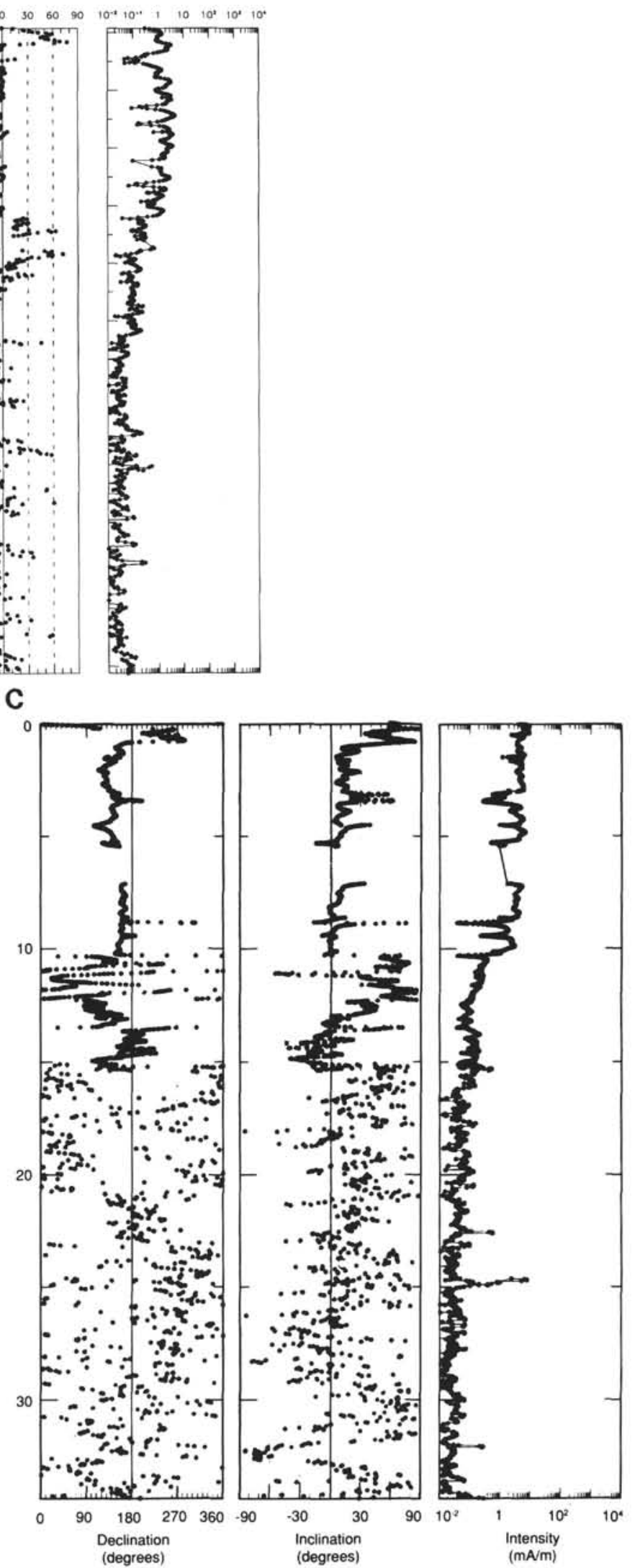

Figure 1. Remanence after 15-mT AF demagnetization. A. Oriented Cores 130-805C-3H to -5H. B. Unoriented Cores 130-806B-1H to -4H. C. Unoriented Cores

$130-806 \mathrm{C}-1 \mathrm{H}$ to $-4 \mathrm{H}$.

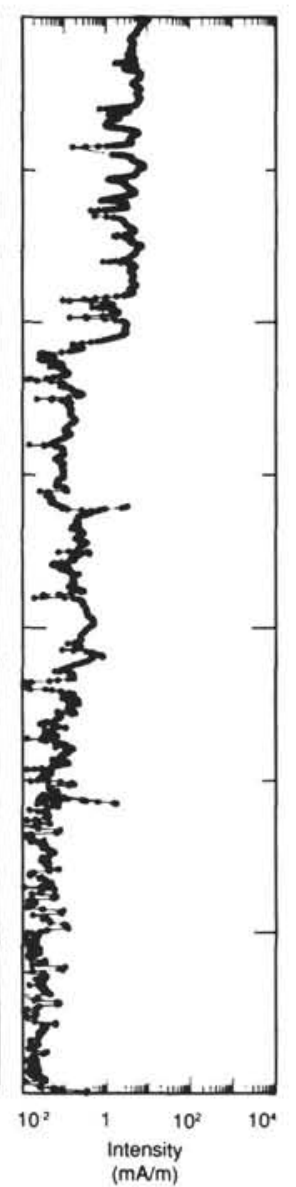


between sites result in a large variation in the oldest chron preserved, from the Cochiti Subchron in the Gilbert Chron at Site 804, to a point still within the Brunhes Chron at Site 806. The sub-bottom depth of the IRE was found to increase with increases in both water depth and latitude (Fig. 2). Both relationships suggest that IRE sub-bottom depth increases with decreasing organic input to the sediments. Increasing latitude away from the equatorial high-productivity zone reduces organic productivity. Greater water depth allows more time for the oxidation of organic matter as it falls through the water column, resulting in a diminished final input of organic matter to the seafloor.

Below the IRE through the lower Pliocene and upper Miocene record, AF-demagnetized intensities for the most part remain near the PCM detection limit. Interpretation was also hampered by the presence of an overprint characterized by steeply inclined negative inclinations $\left(-60^{\circ}\right.$ to $\left.-80^{\circ}\right)$, which are at their most severe at Sites 805 and 806 (Fig. 3), where 15-mT demagnetization reduces remanence intensity to $10 \%$ of the natural remanent magnetization (NRM). Inclinations after demagnetization are widely scattered, but they remained biased toward negative directions. Similar steeply inclined overprints affecting DSDP and ODP cores have been reported by Barton and Bloemendal (1986), Bleil (1989), Tauxe et al. (1989), and Hounslow et al. (1990). Hall and Sager (1990) interpreted a similar overprint affecting Leg 116 sediments as a drilling-induced remanence related to the core barrel, which they found to be intensely magnetized.

Intervals of anomalous overprint magnetization are seen at subbottom depths near the IRE in Sites 806 and 807. In Hole 806B, immediately below the IRE at $10.5 \mathrm{mbsf}$, the AF-cleaned declination and inclination records are complex and remain so to a depth of about $12.5 \mathrm{mbsf}$ (see Figs. 1B-1C). Declination then follows an extraordinary spiralling path through three complete revolutions from the top of Core $130-806 \mathrm{~B}-3 \mathrm{H}$ at $16.0 \mathrm{mbsf}$ down to $21 \mathrm{mbsf}$. Over this interval inclination swings from $+60^{\circ}$ to $-70^{\circ}$ and intensity is increased. Below 21 mbsf the AF-cleaned record becomes chaotic, and intensities decrease again. Complex magnetization features also appear in the record from Hole $806 \mathrm{C}$, extending from immediately below the IRE at $10.3 \mathrm{mbsf}$ down to $15.1 \mathrm{mbsf}$. Similar behavior occurs in Hole 807A (Fig. 4), in which an interval of twisting declination and widely varying inclination occurs, starting just below the IRE at 31 mbsf and continuing to the bottom of Core 130-807A-4H at 36 mbsf.

Twisting of APC cores during their removal from the core barrel has been reported on other ODP legs; however, although this process could rotate declinations, it could not produce the wide and systematic variations in inclination seen over these intervals. In addition, visual examinations of Cores $130-806 \mathrm{~B}-2 \mathrm{H}$ and $-3 \mathrm{H}, 130-806 \mathrm{C}-2 \mathrm{H}$, and $130-807 \mathrm{~A}-4 \mathrm{H}$, within which this complex magnetization occurs, reveal no evidence of physical disruption or internal rotation of the cores. It is difficult to envisage how these features could have arisen as primary magnetization, and they are most easily explained as a drilling-related remanence. Spiraling declination may have resulted from the passage of the core past a locally intense field source in the drill string, core barrel, or on the drill floor, which was rotating relative to the core during the process of core recovery and removal from the core barrel. In Hole $806 \mathrm{~B}$ the interval of spiraling declination is marked by an increase in NRM intensity over the intervals above and below it. The contrast in intensity is more pronounced after AF demagnetization. This behavior, and the resistance of this spurious component to $\mathrm{AF}$ demagnetization in each case where it occurs, suggest that this component has been acquired by a relatively high-coercivity phase.

Drilling-related magnetization may also affect an interval at Site 804 in Core 130-804A-6H (Fig. 5) below 43.5 mbsf. The apparently normal polarity of this interval is out of magnetostratigraphic sequence (Shipboard Scientific Party, 1991), inclination is anomalously high and declines downward, and intensity shows a 20 -cm cycle of rises and falls. Drilling-related remanence, or a combination of drilling remanence and viscous remanence (VRM), appears to affect

\section{Lowest observed stable magnetic polarity (mbsf)}

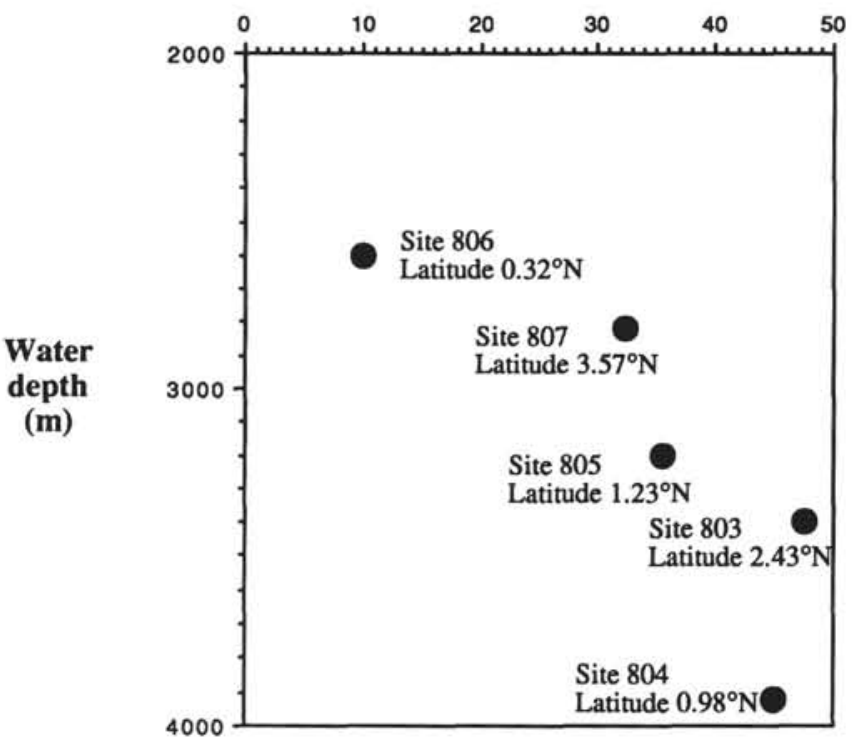

Figure 2. Sub-bottom depth at which magnetic polarity information is lost (= IRE) vs. water depth and latitude.

this interval. The anomalous magnetization again resists AF demagnetization to $15 \mathrm{mT}$.

At Site 803 a gradual increase in intensities with increasing sub-bottom depth occurs in the middle Miocene section. Intensities rise to about $10^{-3}-10^{-2} \mathrm{Am}^{-1}$ and continue at this level through the Oligocene and Eocene carbonate record. This return to higher NRM intensity is accompanied by the appearance of intervals of consistent inclination (Fig. 6). Declinations are relatively scattered as a result of drilling-induced fractures of the core. Polarities of these intervals can be determined for the lower Miocene and Oligocene sequence, for which the paleolatitude of Site 803 (then in the Southern Hemisphere) was just sufficient to allow polarity to be recognized on the basis of inclination alone. A rather discontinuous magnetostratigraphy, which is in broad agreement with the biostratigraphy, was drawn up on this basis. A similar pattern is present in the middle Miocene sequence at the other deeply drilled site, Site 807 , although intensities there return only to about $10^{-4}-10^{-3} \mathrm{Am}^{-1}$, and the recognition of polarity intervals is correspondingly much less continuous.

Measurements of recognizable, consistent inclination after AF demagnetization from Oligocene cores from Hole 803D are distributed with a maximum frequency at $+9^{\circ}$ (Fig. 7), indicating an Oligocene paleolatitude for Site 803 of about $4.5^{\circ}$, within $2^{\circ}$ of the paleolatitude predicted for this site by the Pacific apparent polar wander path (APWP) (Gordon, 1983; Sager and Pringle, 1988). The corresponding peak at $-9^{\circ}$ has been suppressed because the majority of the data represent the interval from Chrons C12 to C10, over which reversed polarities (Southern Hemi-sphere positive inclinations) dominate. A primary DRM (or pDRM) appears to have been isolated by $\mathrm{AF}$ demagnetization in this case.

Analysis of the Miocene to Eocene sequence of Site 807, however, is less clear. The cleaned inclination data can be divided into four intervals: Miocene, late Oligocene, early Oligocene, and Eocene. Expected primary inclinations derived from the Pacific APWP for these intervals are about $\pm 3.5^{\circ}, \pm 8^{\circ}$ to $\pm 11.5^{\circ}, \pm 12^{\circ}$ to $\pm 14^{\circ}$, and \pm 15.5 to $\pm 25^{\circ}$, respectively. Broad frequency maxima for both the Miocene and the late Oligocene AF-cleaned data from Hole $807 \mathrm{~A}$ extend over the range between the negative and positive 


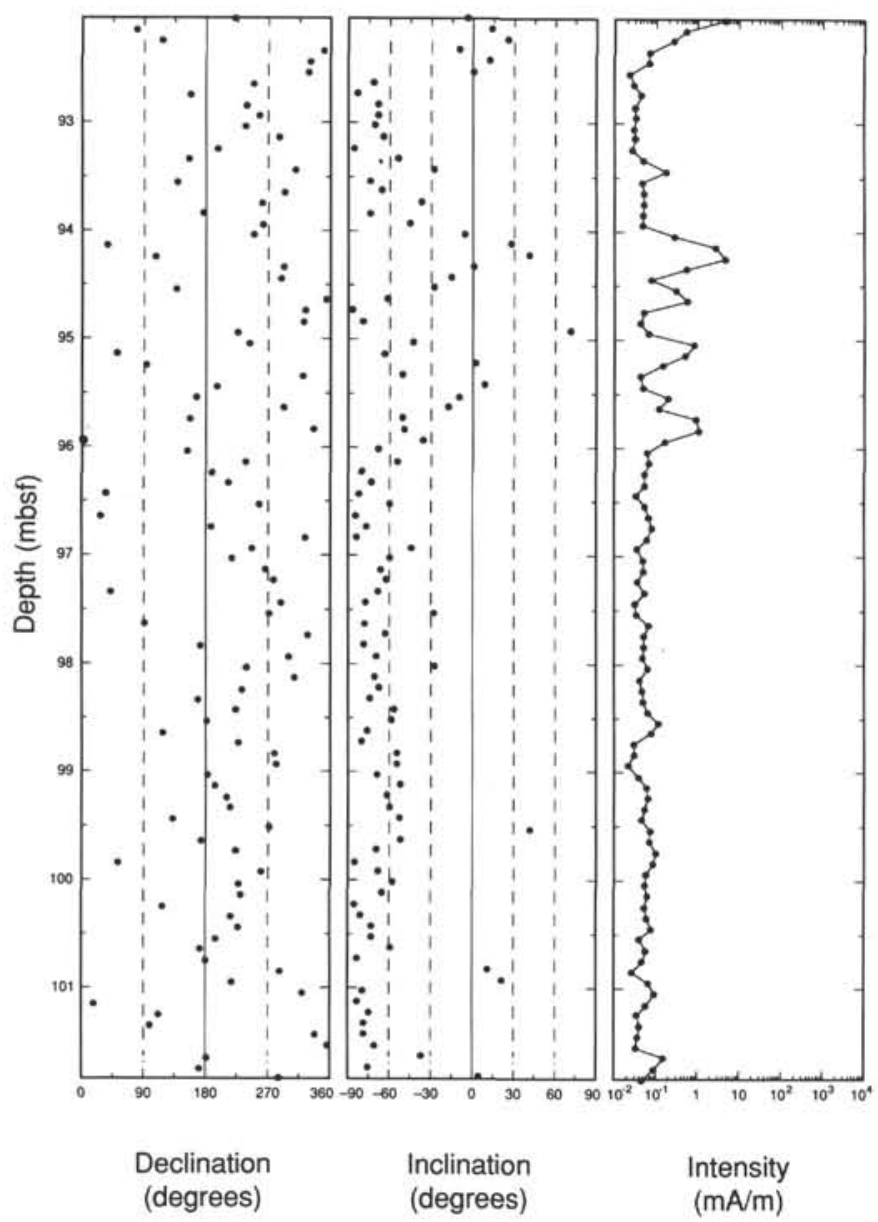

Figure 3. NRM of Core 130-806B-11H. Note the steeply negative inclinations.

expected inclinations, but both distributions are biased toward steeper negative inclinations (Fig. 8). The presence of both a primary magnetization and an overprint that has resisted the 15-mT demagnetization can be inferred for this part of the sequence. The peak of the AF-cleaned, early Oligocene inclination frequency (Fig. 9) occurs at $+6^{\circ}$, essentially the inclination expected at this site for a VRM acquired over the Brunhes Chron. Primary magnetizations from the early Oligocene sequence have apparently been completely or largely replaced by VRM. The Eocene AF-cleaned inclinations have a peak frequency at $-22^{\circ}$, suggesting that a normal primary magnetization has been preserved over this part of the sequence at this site. The equivalent positive inclination peak is suppressed, which may suggest an excess of normal polarity over the intervals represented. Overprinting could also be a source of a bias toward negative inclinations, however, and cannot be ruled out.

\section{Discrete Samples}

\section{Site 803}

The shallowest sample, $130-803 \mathrm{C}-1 \mathrm{H}-2,74-76 \mathrm{~cm}$, is weakly magnetized $\left(\mathrm{NRM}=4 \times 10^{-5} \mathrm{Am}^{-1}\right)$ and unstable when demagnetized. Samples below the top core but above the IRE exhibit demagnetization paths with relatively low noise levels. After removal of soft components at $5 \mathrm{mT}$, little further change takes place in direction or intensity up to $20 \mathrm{mT}$. Demagnetization above $20 \mathrm{mT}$ usually proceeds along a fairly linear, low inclination path, but subtle changes in direction are present through the higher demagnetization steps. The last few steps commonly trend slightly away from convergence on the origin of the orthogonal plot, and $5 \%-25 \%$ of remanence remains at $50 \mathrm{mT}$ (Fig. 10A).

An abrupt change occurs in demagnetization character beginning with Samples 130-803D-5H-2, 74-76 cm (33.24 mbsf), and 130$803 \mathrm{C}-4 \mathrm{H}-2,86-88 \mathrm{~cm}$ ( $49.86 \mathrm{mbsf})$. From this point down to about 210 mbsf (Core 130-803D-24H), the samples are characterized by inconsistent and scattered demagnetization behavior, with NRM intensities from about $1 \times 10^{-5}$ to $5 \times 10^{-5} \mathrm{Am}^{-1}$. Where demagnetization is not completely randomized, roughly linear segments can be recognized at intermediate coercivities from about 10 to $35 \mathrm{mT}$, but these fail to converge (to varying degrees) on the origin of the plot, suggesting the presence of a further component or components (Fig. 10B). Demagnetization vectors from 35 to $50 \mathrm{mT}$ are closely grouped and from $20 \%$ to $40 \%$ of NRM persists at $50 \mathrm{mT}$, indicating the high coercivity of this component. Although the high-coercivity component(s) could not be isolated, its inclination appears to be close to zero. Inclinations of the intermediate coercivity segment vary from $0^{\circ}$ to $\pm 15^{\circ}$.

Below 210 mbsf (Core 130-803D-25X), NRM intensities of samples from Hole 803D gradually increase until they reach $10^{-2}$ $\mathrm{Am}^{-1}$ in Sample 130-803D-40X-3, 103-105 cm. Many samples over this interval (which extends from the middle Miocene down to the upper Oligocene) display four distinct stages of demagnetization, in some variation on the following (Fig. 10C). Little change occurs from the NRM to $15 \mathrm{mT}$, except in some cases for the removal of a small component by $5 \mathrm{mT}$. Over the short interval from about 15 to $25 \mathrm{mT}$, inclination of the successive removed components ("difference vectors") decreases slightly. Above $25 \mathrm{mT}$ the pattern repeats; the inclination of the difference vectors first increases slightly again, then decreases to near zero by $40-45 \mathrm{mT}$. Declination does not change much over either of these intervals. From 40 to $50 \mathrm{mT}$ the difference vectors may suddenly change direction, and about $10 \%$ of the NRM remains at $50 \mathrm{mT}$. Other samples are similar, but the repetition of the inclination pattern is less clearly developed in some cases, particularly in the deeper samples. The two intermediate stages may be explained by a repeated pattern of a small overprint of the steeply inclined component (probably a drilling remanence) over a low-inclination component (either a primary or diagenetic magnetization or a VRM). Repetition of the pattern is presumably caused by the presence of two different phases with differing coercivity spectra. The final demagnetization stages represent a trend toward one or more magnetization components held by higher coercivity domains, which are not isolated.

Demagnetization of chalk and limestone samples from below 420 mbsf (lower Oligocene to middle Eocene) was conducted thermally. Thermally soft components were removed below $200^{\circ}$ to $300^{\circ} \mathrm{C}$. Complex changes in direction over the interval between about $400^{\circ}$ and $525^{\circ} \mathrm{C}$ were superimposed on an otherwise linear, convergent path (Fig. 11A). Between $575^{\circ}$ and $600^{\circ} \mathrm{C}$ (i.e, the Curie point of end-member magnetite), the NRM was usually totally destroyed, other than for small amounts of random noise. Exceptions are middle Eocene Samples 130-803D-64X-CC, 16-18 cm; -65X-CC, 7-9 cm; and $-67 R-1,32-35 \mathrm{~cm}$ (the deepest samples treated) and perhaps also Sample 130-803D-49X-2, 56-58 cm, from the lower Oligocene. These appear to continue to demagnetize systematically up to $625^{\circ} \mathrm{C}$, at which stage a small component still remains (Fig. 11B).

\section{Site 804}

Samples from Hole $804 \mathrm{C}$ above the IRE generally resemble those from the equivalent interval at Site 803 , but they demagnetize more continually over the interval from 5 to $20 \mathrm{mT}$ (Fig. 12A). Samples $130-804 \mathrm{C}-2 \mathrm{H}-2,130-132 \mathrm{~cm}$, and $-4 \mathrm{H}-4,59-61 \mathrm{~cm}$ (Fig. 12B), have a larger proportion of NRM remaining at $50 \mathrm{mT}$.

In the upper Miocene sequence between Cores 130-804C-6H (where the IRE occurs) and 130-804C-13H (110 mbsf), intensities are 
A

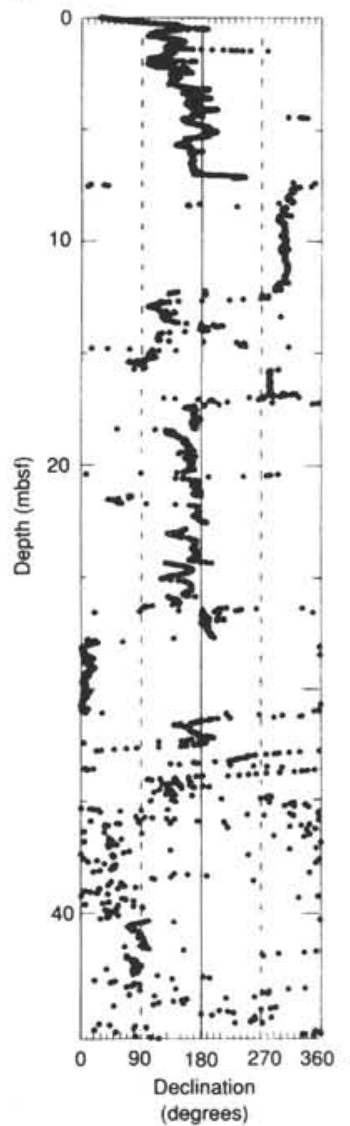

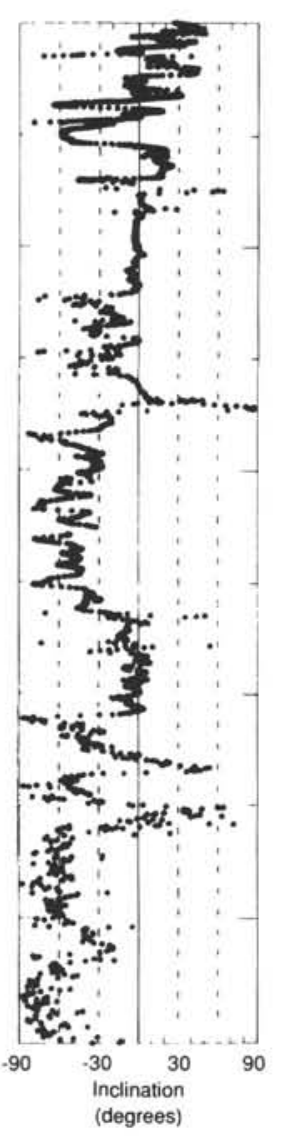

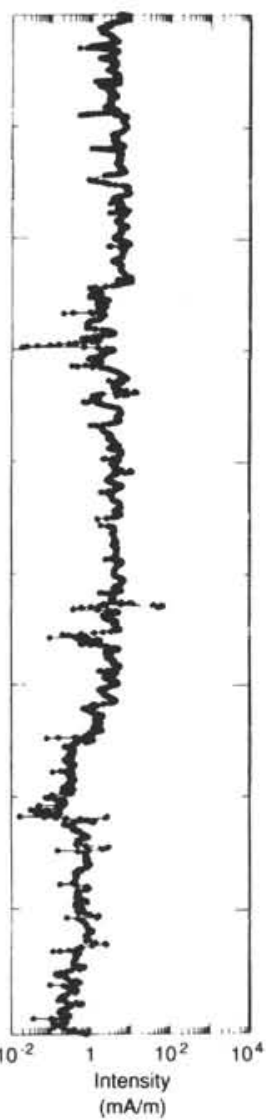

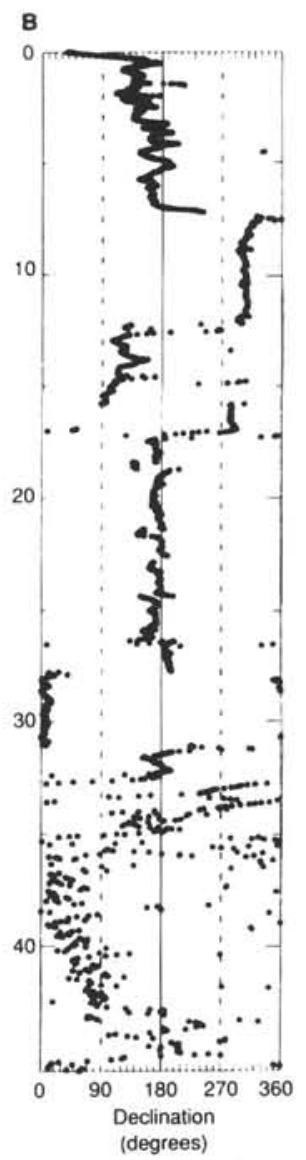
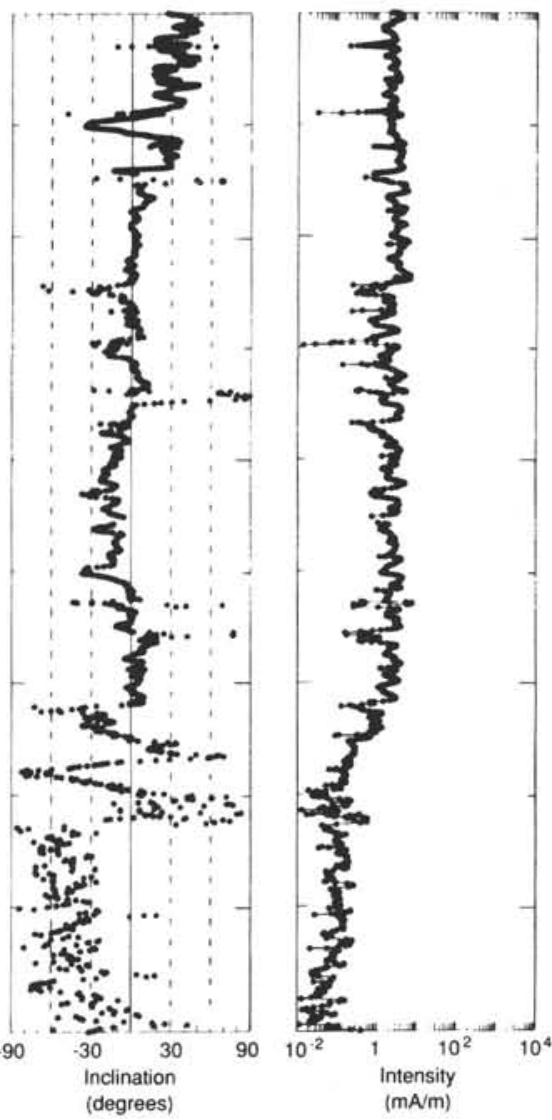

Figure 4. NRM (A) and AF demagnetized (B) remanence of Cores 130-807A-1H through -5H. Cores 130-807A-3H to -5H (16.9-45.4 mbsf) have been oriented.

$<5 \times 10^{-5} \mathrm{Am}^{-1}$. Demagnetization is too noisy to be useful beyond $10 \mathrm{mT}$. Intensities of the samples from below Core $130-804 \mathrm{C}-13 \mathrm{H}$ recover as they did at Site 803 . Repeated intervals of slight steep-toshallow trends in the difference vectors with increasing demagnetization can be recognized in samples from the middle Miocene to lower Oligocene sequence of Hole $804 \mathrm{C}$, as they were in samples from the middle Miocene to upper Oligocene section of Hole 803D (Fig. 13A). Demagnetization from Hole 804C differs, however, in that the overall inclinations are generally steeper (indicating a larger contribution from the drilling remanence), a proportionally large high-coercivity component ( $50 \%$ or more of NRM remaining at $50 \mathrm{mT}$ ) is commonly present, and remanence changes significantly over the demagnetization interval from 5 to $15 \mathrm{mT}$ (Fig. 13B).

\section{Sites 805 and 806}

The AF demagnetization of samples from Sites 805 and 806 follows much the same pattern as at Site 804 , although there is, if anything, a tendency for even more dominance of the steeply inclined drilling remanence, some of which is carried by a high-coercivity phase at Site 806 (Fig. 14). Stable demagnetization in Hole 805B is again lost below the IRE until it returns accompanying an increase in intensity from Core 130-805B-38X (350 mbsf, in the middle Miocene sequence) downward. The return of stable demagnetization in Hole 806B occurs in the middle Miocene sequence somewhere between Core 130-806B-40X (380 mbsf), where AF demagnetization was discontinued, and Core 130-806B-53X (490 mbsf), where thermal demagnetization of the samples was begun.
Thermal demagnetization of the chalk samples from Site 805 began in the lower Miocene sequence at Core 130-805B-49X (460 mbsf). The first few samples demagnetize noisily above $350^{\circ} \mathrm{C}$ (Fig. 15A); however, from Core 130-805C-54X (510 mbsf) down, demagnetization becomes highly linear and convergent on the origin above $250^{\circ}-300^{\circ} \mathrm{C}$, with only minor noise between $400^{\circ}$ and $550^{\circ} \mathrm{C}$ (Fig. 15B). The NRM is almost totally removed at the step from $575^{\circ}$ to $600^{\circ} \mathrm{C}$. Chalk samples from Site 806 remain weakly magnetized (NRMs $<10^{-4} \mathrm{Am}^{-1}$ ), demagnetize very noisily, and are commonly uninterpretable (Fig. 15C).

\section{Site 807}

Thermal demagnetization of dried oozes from above the IRE in Hole $807 \mathrm{~A}$ follows a simple, linear, convergent path, with only a small amount of noise generated above $300^{\circ} \mathrm{C}$ (Fig. 16A). Below the IRE, demagnetization becomes extremely noisy (Fig. 16B) and the only pattern that can be discerned is that difference vectors below about $150^{\circ} \mathrm{C}$ tend to be steeply inclined. Interpretable demagnetization returns in the middle Miocene sequence with an increase in NRM to about $5 \times 10^{-4} \mathrm{Am}^{-1}$ in Core 130-807A-42X (390 mbsf). Thermal demagnetization of plastic-boxed oozes and chalks from this core down to Core 130-807A-46X (430 mbsf) follows simple linear paths with a small generation of noise from $350^{\circ}$ to $500^{\circ} \mathrm{C}$ (Fig. 16C).

Below this sub-bottom depth, NRM intensities of the boxed soft chalks decline by an order of magnitude, and demagnetization paths become noisy again. Cylinder samples drilled from the harder chalks show the same pattern, the intensity decline beginning slightly deeper 


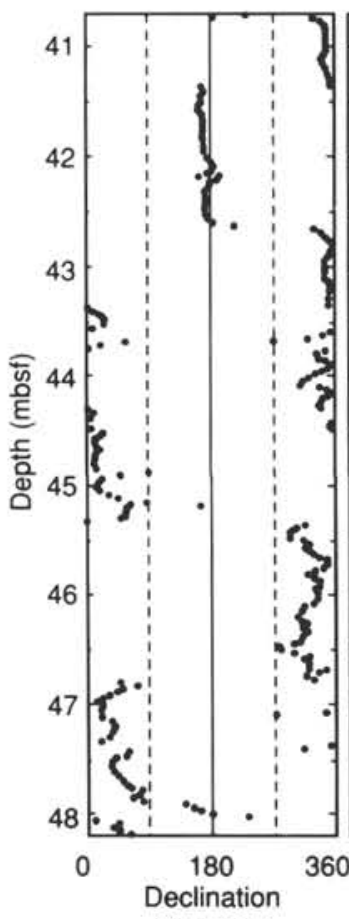

(degrees)

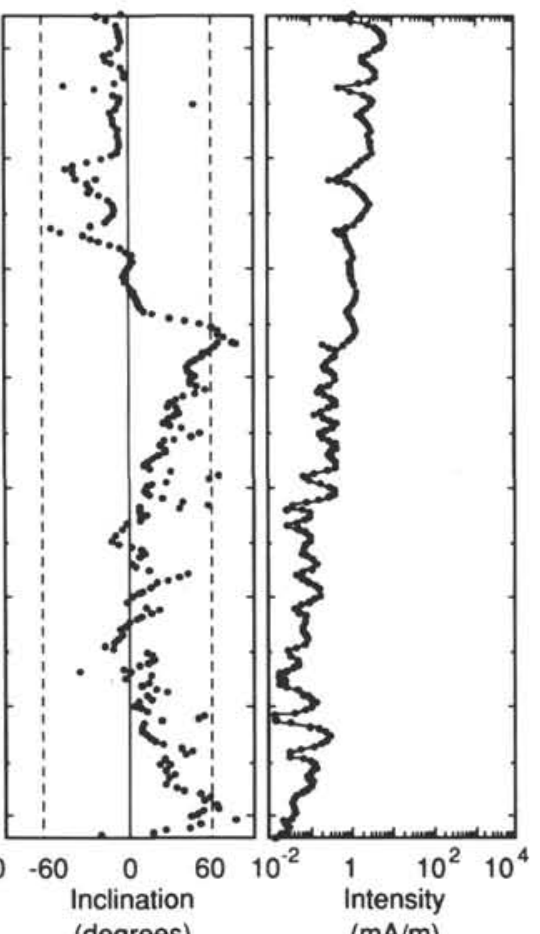

(degrees)

$(\mathrm{mA} / \mathrm{m})$
Figure 5. Oriented, demagnetized remanence from Core 130-804A-6H.

with Core 130-807A-54X (508 mbsf). The NRM increases to about $10^{-3} \mathrm{Am}^{-1}$ from Core 130-807A-64X (600 mbsf, in the upper Oligocene) downward, demagnetization becomes highly linear and convergent, and some samples demagnetize systematically to temperatures beyond the magnetite Curie point (Fig. 17A). Intensities decline again to as little as $3 \times 10^{-5} \mathrm{Am}^{-1}$ below Core 130-807 A-75X (707 mbsf, in the lower Oligocene), and demagnetization paths again become noisy, remaining so until the bottom of Hole $807 \mathrm{~A}$ at 823 mbsf. Inclinations over this last interval are usually low (Fig. 17B).

Core recovery from Hole $807 \mathrm{C}$ began at $780 \mathrm{mbsf}$, and the pattern of low-intensity, noisy demagnetization and low inclinations continues to apply to most samples in this hole down to Core 130-807C-46R (1140 mbsf), which was dated to the base of the early Eocene and contained the deepest sample studied. Scattered samples through Hole $807 \mathrm{C}$ had intensities as high as $4 \times 10^{-3} \mathrm{Am}^{-1}$. These fall into two categories (Fig. 18): those that demagnetize toward an inclination of around $\pm 20^{\circ}$, and those that trend toward an inclination very close to zero. Sample 130-807C-38R-1, 27-28 cm, includes a segment from $350^{\circ}$ to $450^{\circ} \mathrm{C}$ with an inclination of about $-20^{\circ}$ (i.e., normally polarized) within two similar horizontal segments.

\section{Isothermal Remanence Acquisition}

Patterns of IRM acquisition in samples from Hole 803D (Fig. 19) reveal the presence of a very high coercivity phase. Magnetite is saturated by fields of $0.2 \mathrm{~T}$ (Banerjee and O'Reilly, 1967; Ishikawa, 1967), but samples from both the oozes and chalks below the IRE show a continuing increase in IRM with applied fields above $0.2 \mathrm{~T}$; saturation is not achieved until at least 1.0 T. Above the IRE the analysis is less clear, as the high-coercivity signal is swamped by noise from the much larger saturated magnetite IRM; there may be a small upward trend in IRM above $0.2 \mathrm{~T}$ in samples below Core 130-803D$2 \mathrm{H}$. High-coercivity IRM peaks in intensity in Core 130-803D-6H, just below the IRE. A set of 10 samples that had been allowed to dry out was compared with an equivalent set that was still wet to determine if drying had altered the high-coercivity phase. Drying consis-

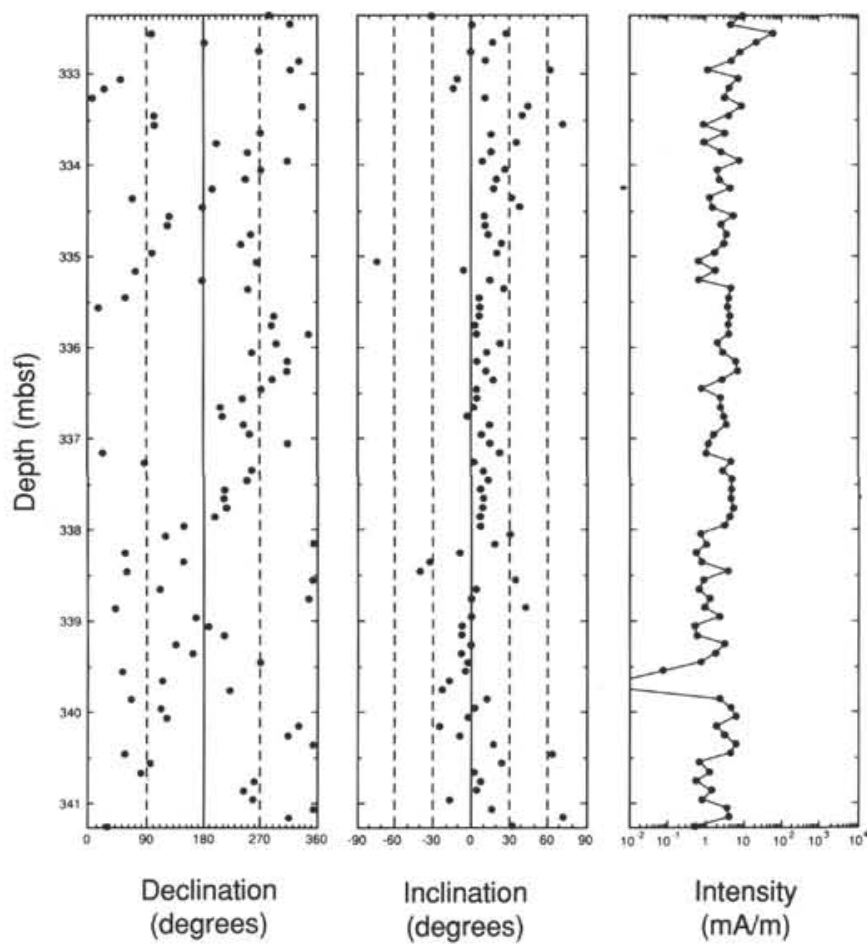

Figure 6. Remanence after AF demagnetization in Core 130-803D-37X, showing intervals of consistent low positive (335-338 mbsf) and low negative (338.7$339.5 \mathrm{mbsf}$ ) inclinations, together with intervals of scattered inclinations.

tently reduced both the total saturation IRM and the proportion acquired above $0.2 \mathrm{~T}$ in samples below the IRE.

\section{Intensity and Sulfate Concentration}

Interstitial water sulfate levels and remanence intensity are positively correlated (Fig. 20). Sulfate levels show a broad decline that extends over the IRE. At all five sites the IRE corresponds to a sulfate concentration that (on interpolation of the sulfate curve) is consistently between 26 and $26.7 \mathrm{mM}$, irrespective of the total sulfate depletion, which is inversely dependent on water depth (Delaney et al., 1991). Each sulfate profile also shows a small local maximum within the overall decline, both above and below the IRE and at sub-bottom depths ranging from about 20 to about $50 \mathrm{mbsf}$.

\section{Organic Carbon Content}

Total organic carbon from the uppermost sample from each site varies inversely with the sub-bottom depth of the critical intensity drop (Table 1 and Fig. 21). The average TOC content over the uppermost 10 and $50 \mathrm{~m}$ is similarly correlated for each of the sites except Site 807.

\section{DISCUSSION}

Magnetic diagenesis in sediments is the sum of two competing processes related to microbially mediated oxidation of organic material (Karlin and Levi, 1983). Iron reduction begins after the consumption of free oxygen and the reduction of labile $\mathrm{MnO}_{2}$ and $\mathrm{NO}_{3}^{-}$. Initial microbial reduction of hydrated iron (III) oxides to produce magnetite (Mann et al., 1984) supplements detrital magnetite deposition and significantly enhances the remanence intensity. Unit cell sizes of such authigenic magnetite indicate little or no titanium content. Magnetite generation has been reported to occur near a change in color of the 


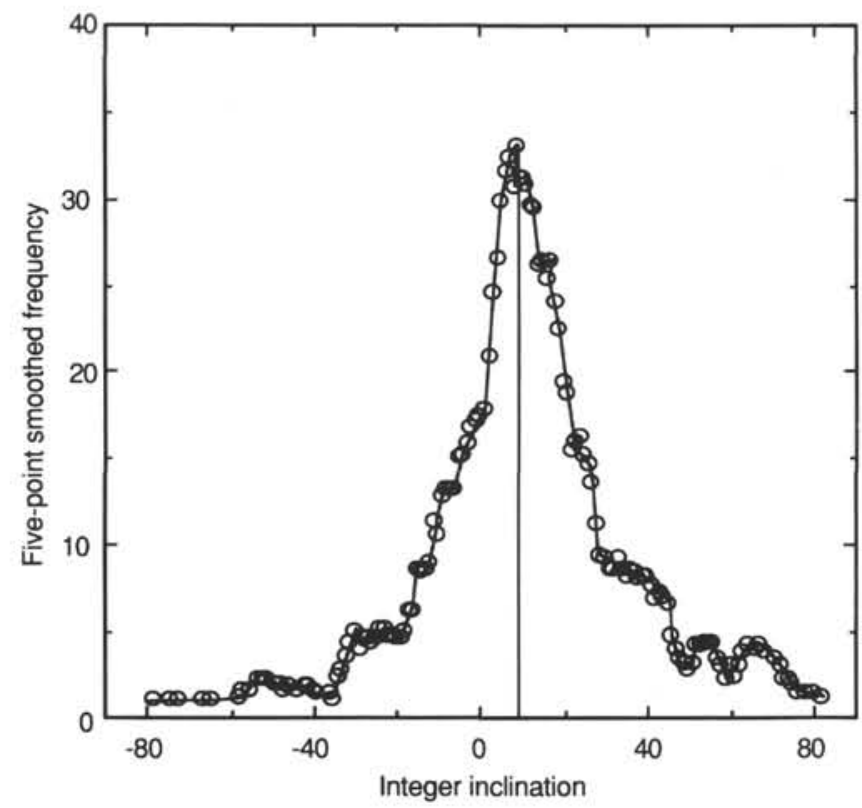

Figure 7. Smoothed frequency plot of inclination from lower Miocene and Oligocene cores, Hole 803D. The mode at $+9^{\circ}$ is indicated.

Table 1. Total organic carbon content (percent) from shore-based studies.

\begin{tabular}{llllll}
\hline \multicolumn{1}{c}{ Hole } & 803D & $804 \mathrm{C}$ & $805 \mathrm{C}$ & $806 \mathrm{~B}$ & $807 \mathrm{~A}$ \\
\hline Core 1, Sect. 1 & 0.073 & 0.125 & 0.179 & 0.245 & 0.169 \\
Top 10 mbsf & 0.062 & 0.119 & 0.123 & 0.166 & 0.103 \\
Top 50 mbsf & 0.064 & 0.100 & 0.111 & 0.154 & 0.076 \\
\hline
\end{tabular}

sediments from tan to green, marking the transition from Fe-oxidizing to Fe-reducing conditions (Karlin et al., 1987).

No continuous zone of abruptly increasing NRM intensity, which could mark authigenesis of magnetite, was observed in any holes from Leg 130, and sediment colors usually changed from brown (10 YR $6 / 3$ ) to light gray or white in the first $10 \mathrm{mbsf}$, without an obvious green stage. The high Curie point (between $575^{\circ}$ and $600^{\circ} \mathrm{C}$ ) observed for samples above the IRE indicates the presence of nearly pure end-member magnetite, which suggests that at least some authigenic magnetite is nevertheless present. The scarcity of domains with AF coercivities between 5 and $15 \mathrm{mT}$ at Site 803 may also indicate microbial generation of magnetite, which results principally in singledomain or pseudo-single-domain grains with coercivities $>30 \mathrm{mT}$ (Karlin et al., 1987). Carbonate oozes from Holes 632A and 633A from Leg 101 show a similar progression of colors over the first $10 \mathrm{mbsf}$; they also show no increase in NRM intensity over this interval. Nevertheless, Sager (1988) attributed the strong magnetization of these sediments, which are isolated from significant terrigenous input, to biogenic sources. It is likely that a significant proportion of the magnetite in the Leg 130 oozes is also biogenic. In both the Leg 130 and the Leg 101 oozes, magnetite authigenesis may have occurred in very poorly consolidated sediment within the first meter below the sediment-water interface, which may have not have been sampled, or which may have been washed out during retrieval and on-deck handling of the core.

Microbial reduction of iron may proceed through an additional step in which magnetite and other iron oxides are dissolved, freeing $\mathrm{Fe}$ (II) (Karlin and Levi, 1983, 1985). The dramatic intensity drop seen at Leg 130 sites can be ascribed to this process. Sulfate reduction is also microbially driven; Karlin and Levi (1983) reported a study of two noncarbonate cores in which sulfate reduction occurs independently of, and somewhat later than, iron oxide reduction. In Leg 130
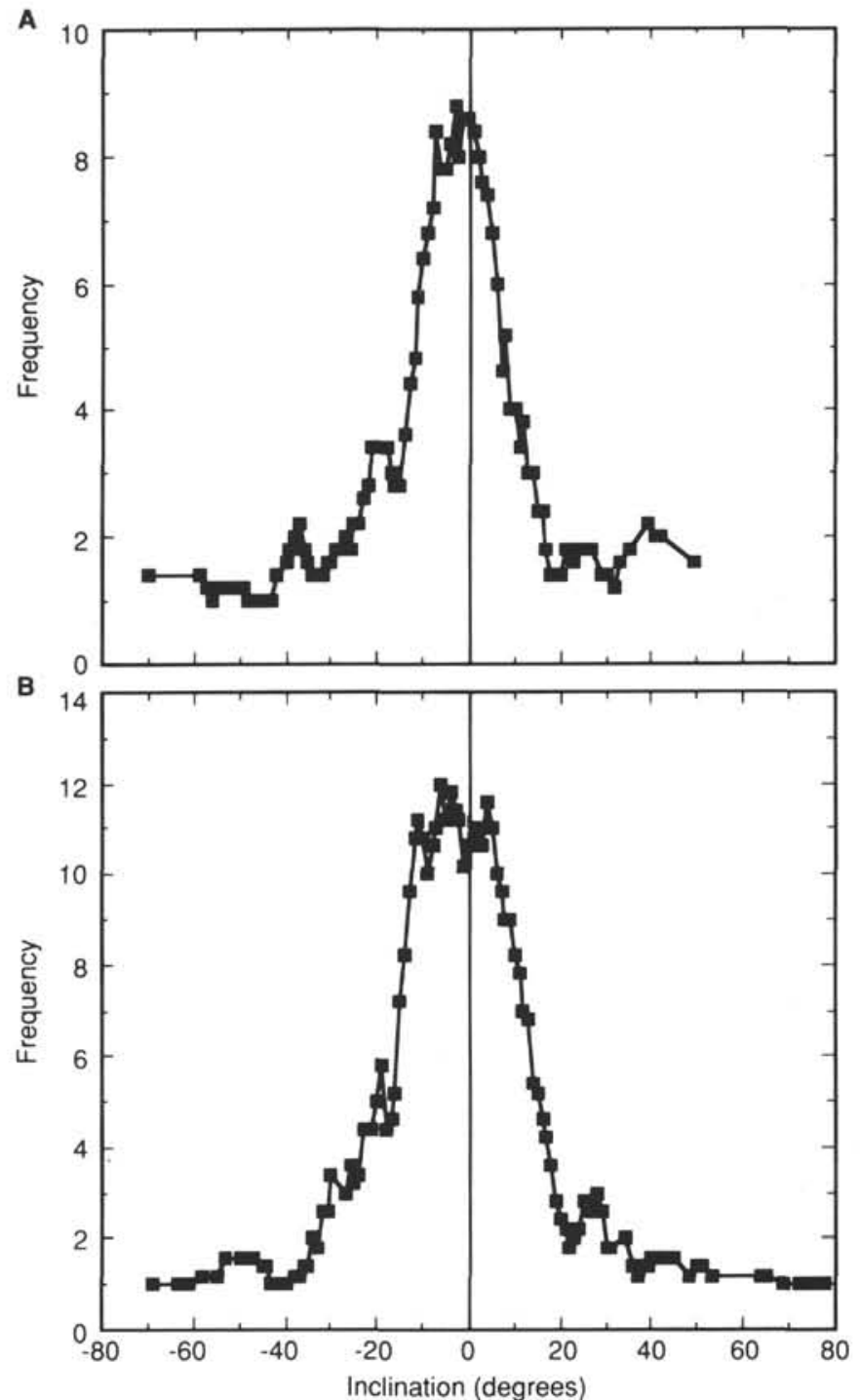

Figure 8. Smoothed frequency plot of inclination from Hole 807A. A. Cores 130-807A-46X through -49X (lower to middle Miocene). B. Cores 130-807A$64 \mathrm{X}$ through $-72 \mathrm{X}$ (upper Oligocene).

holes sulfate reduction is a continuous process extending across the IRE; the sudden acceleration in magnetite reduction is linked to a very precise sulfate concentration, suggesting that both processes are similarly dependent on the overall oxidation state.

The relationship between water depth, latitude, and sub-bottom depth of the IRE implies an organic input control on the overall rate of iron and sulfate reduction. Increased productivity occurring near the equator, and increased survival of organic material down to the seafloor that follows from shallower water depths, both contribute to more rapid reduction. This relationship is confirmed by the TOC measurements for all sites except Site 807 , which has an anomalously low TOC.

Reduction of both iron oxides and sulfate leads to pyrite formation. Intermediate steps involve the production of metastable amorphous $\mathrm{FeS}$ and mackinawite; less reduced conditions proceed from mackinawite by way of greigite $\left(\mathrm{Fe}_{3} \mathrm{~S}_{4}\right)$ (Schoonen and Barnes, 1991a, 1991b). Greigite is metastable and is known to be highly magnetic, but little else is known of its magnetic properties. Krs et al. (1990) noted a high (possibly saturation) IRM in a sample of greigite at an applied field of $0.3 \mathrm{~T}$ and showed that thermal demagnetization completely removed greigite remanence by about $350^{\circ} \mathrm{C}$. Greigite appears to 
A

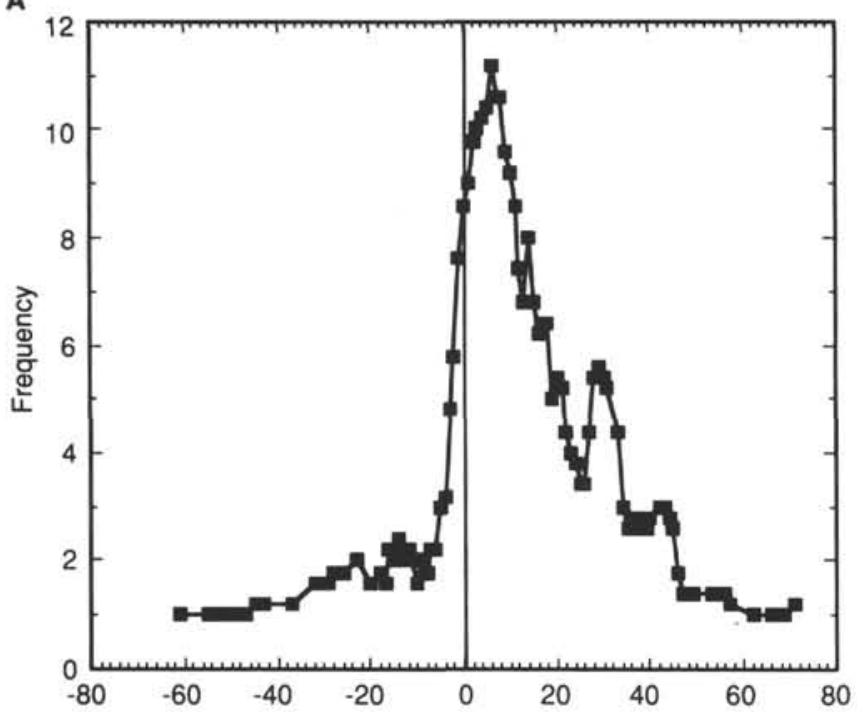

B

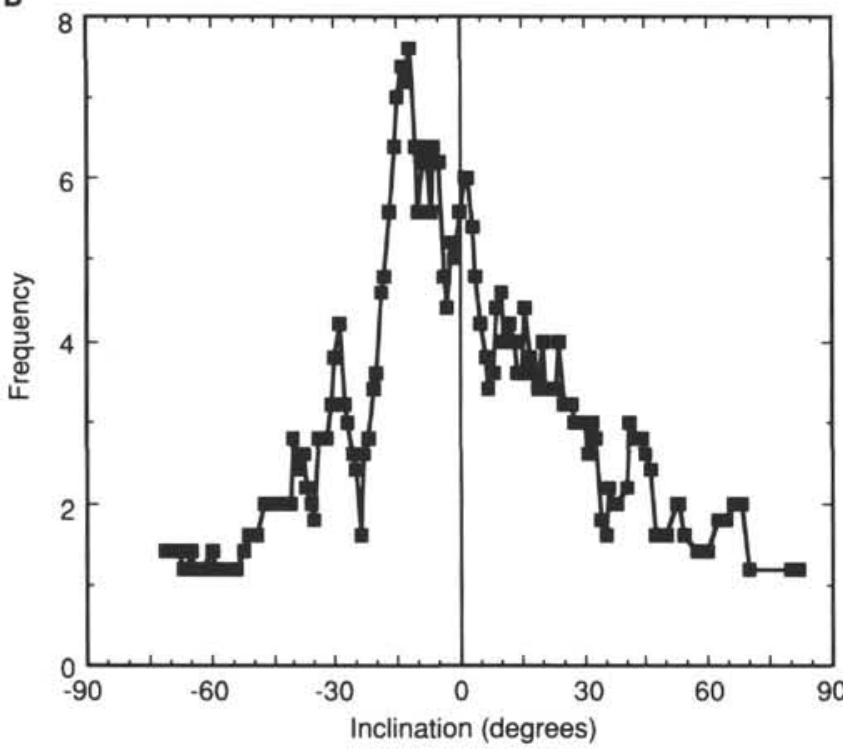

Figure 9. Smoothed frequency plot of inclination from Hole 807C. A. Cores 130-807C-2R, -4R, -6R, -9R, -12R, -15R, and -17R (lower Oligocene). B. Cores $130-807 C-19 R,-23 R$ through $-26 R,-30 R,-35 R,-37 R,-38 R$, and $-40 \mathrm{R}$ (Eocene).

physically decompose at temperatures up to about $300^{\circ} \mathrm{C}$. Continued heating in air above $400^{\circ}-450^{\circ} \mathrm{C}$ results in the generation of secondary magnetite and its further oxidation to hematite (R.L. Reynolds, pers. comm., 1991). Magnetic intensity and susceptibility of sediments in which greigite was identified by X-ray diffraction (XRD), and which were stored wet after sampling, decreases (Snowball and Thomson, 1988; Kalcheva et al., 1990). This reduction occurs only if the samples have been exposed to air (Snowball and Thomson, 1990) and continues if the samples are subsequently allowed to dry out.

Greigite has been recognized as a carrier of a stable, diagenetic chemical remanence in certain cases (Snowball and Thomson, 1990; Kalcheva et al., 1990), although its magnetic stability has been regarded as suspect by Krs et al. (1990). Pyrrhotite of a composition close to $\mathrm{Fe}_{7} \mathrm{~S}_{8}$ is also strongly ferromagnetic with a Curie temperature of $320^{\circ} \mathrm{C}$ (Tarling, 1983). Pyrrhotite is more thermodynamically stable than greigite (Berner, 1967). Recognized by direct optical observation, pyrrhotite has been identified as a mag- netic carrier in sediments of the Cement oil field (Reynolds et al., 1990), where it is genetically linked to the passage of hydrocarbons. XRD analyses indicated the presence of pyrrhotite in highly reduced sediments from the Japan Sea (Kobayashi and Nomura, 1972); thermal demagnetization of these sediments in air showed the pyrrhotite to have a Curie point of about $380^{\circ} \mathrm{C}$, and indicated that the decomposition and oxidation of the pyrrhotite produced secondary magnetic phases above $400^{\circ} \mathrm{C}$, in a pattern similar to that of greigite, but at rather higher temperatures.

In his study of Leg 101 carbonate sediments, Sager (1988) recognized a progressive rise with increasing sub-bottom depth in the mean destructive field (MDF) required to demagnetize samples below an initial reduction accompanying dissolution of magnetite. Sager (1988) attributed this behavior to the generation of magnetic iron sulfides and offered either pyrrhotite or greigite as candidates. Sager noted that the instability of these sediments under thermal demagnetization could be related to thermal decomposition of the sulfides, and noted the alteration of greigite at low temperatures. Very similar behavior applies to the Leg 130 samples: high MDFs are indicated by the acquisition of drilling-induced and VRM overprints that are resistant to AF demagnetization. High MDFs correspond to the high applied field required for IRM saturation. Hematite, which is also characterized by high coercivity, would not have survived in an environment sufficiently reducing to dissolve the less oxidized magnetic oxide magnetite. Weakly magnetized samples, in which the iron sulfide appears to be the dominant magnetic carrier, begin to show large amounts of demagnetization noise at quite low temperatures $\left(100^{\circ}-150^{\circ} \mathrm{C}\right)$. Thermal demagnetization produces a second phase of noise superimposed on the demagnetization path from $400^{\circ}$ to $550^{\circ} \mathrm{C}$ in many samples, consistent with the generation of secondary magnetite. Magnetic iron sulfides again appear to be the origin of this behavior in the Leg 130 carbonates; in this case the argument for greigite as the magnetic sulfide is strengthened by the apparent reduction in IRM saturation and high-coercivity remanence that accompanied drying in air. Higher fields appear to be required for saturation than were apparent in the greigite sample studied by Krs et al. (1990). Coercivity is highly dependent on grain size and shape, however, and the greigite fraction separated by Krs et al. may have been relatively large grained, and hence dominated by multidomain, low-coercivity behavior. The possibility that the sulfide carrier is dominantly pyrrhotite, in which high-coercivity behavior has been demonstrated (Kligfield and Channell, 1981), cannot be completely discounted, however.

Drilling-related, high-inclination remanences dominate the NRM in the weakly magnetized interval below the IRE in all holes, and the anomalous, high-coercivity magnetizations seen in Holes 804A, 806B, $806 \mathrm{C}$, and $807 \mathrm{Aoccur}$ within a 10 -minterval below the IRE. This interval also marks the peak in high-coercivity IRM, which indicates that this interval has the highest proportion of greigite. It appears that the greigite is particularly susceptible to acquiring drilling-related overprints, whereas the high coercivity of this phase makes the removal of these overprints by $\mathrm{AF}$ demagnetization particularly difficult.

Continued sulfate reduction is accompanied by the conversion of some of the greigite to pyrite, leading to lower proportions of highcoercivity IRM (and possibly also to a reduced sensitivity to drillingrelated remanences) deeper in the sequence.

The stratigraphic positions of the minor local sulfate maxima seen at each site do not represent the same age from site to site, nor are they correlated in any simple way with water depth and/or latitude, and they are all substantially younger than the equator crossing age. No clear relationship with organic productivity or initial sulfate input can be seen. Competing reduction of sulfate and other oxides may play a role here; complex, repeated redox patterns (possibly of manganese) were indicated by color bands, which were ubiquitous in the oozes.

The high-coercivity IRM signal at Site 803 first appears to be present in Core 130-803D-2H, about $30 \mathrm{~m}$ above the IRE. High- 
A

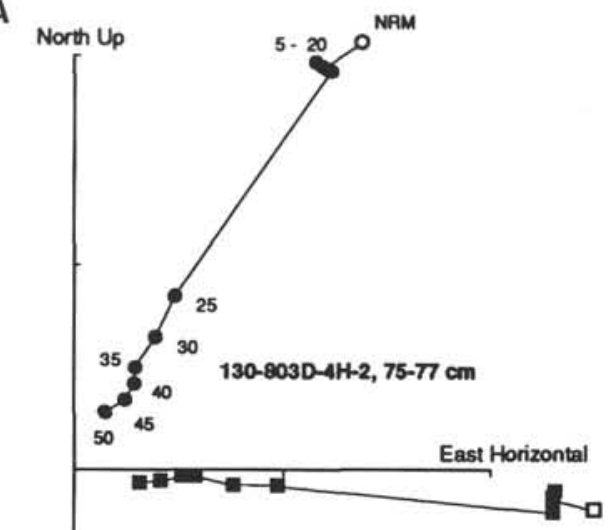

Scale: 1 division $=1 \mathrm{~mA} / \mathrm{m}$

AF demagnetization ( $\mathrm{mT}$ )

South Down

B
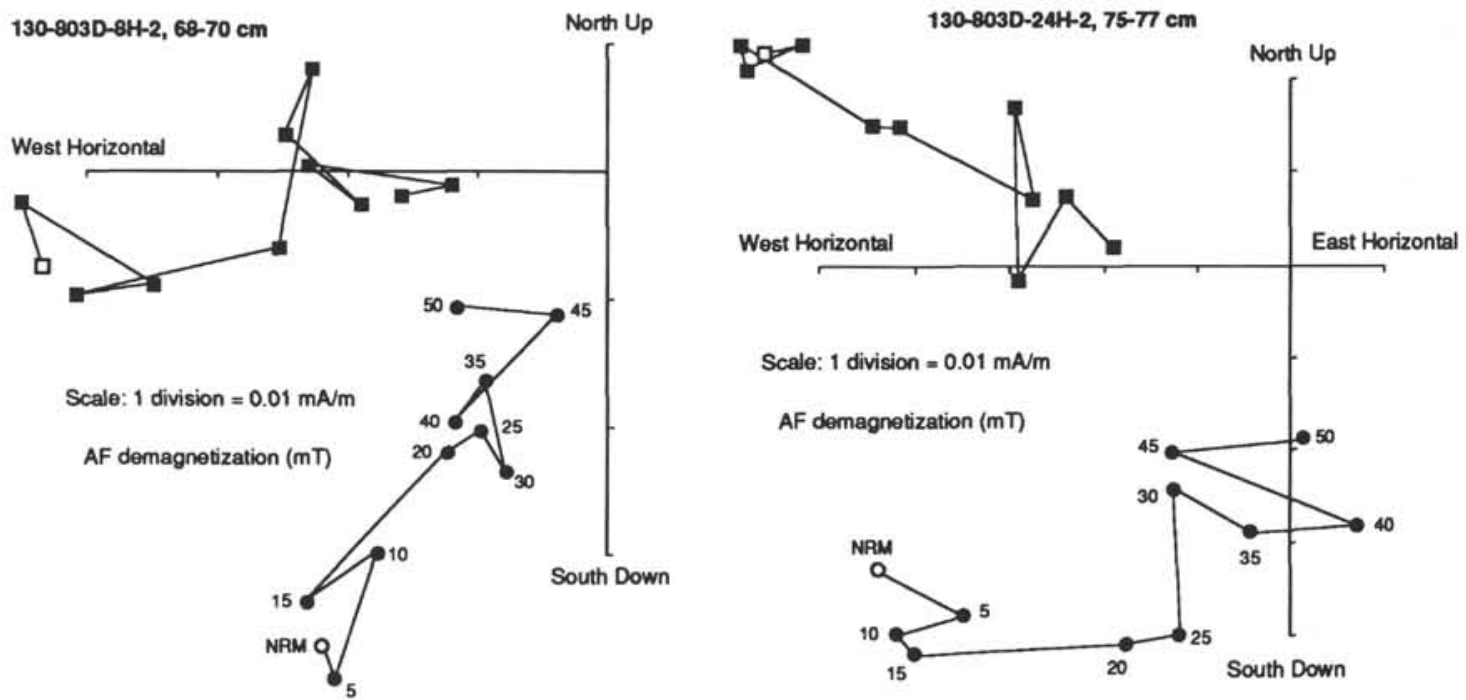

Figure 10. Cartesian (As-Zijderveld) demagnetization plots of samples from Site 803. A. Sample 130-803D-4H-2, 75-77 cm, from the interval above the IRE. B. Samples $130-803 \mathrm{D}-8 \mathrm{H}-2,68-70 \mathrm{~cm}$, and $-24 \mathrm{H}-2,75-77 \mathrm{~cm}$, from the weakly magnetized interval between the IRE and 210 mbsf. C. Samples 130-803D-27X-2, 75-77 cm, and -32X-3, 42-44 cm, from between 210 and $420 \mathrm{mbsf}$, where NRM intensity increases again. Circles represent declination (horizontal plane), squares represent inclination (vertical plane, oriented in the direction of declination for each separate demagnetization step). Open symbols show NRM direction. Samples are unoriented, so declination is arbitrary. AF steps in $\mathrm{mT}$.

coercivity components are also apparent in the AF demagnetization of samples above the IRE in Hole $804 \mathrm{C}$. Both features indicate that greigite first appears above the level of severe magnetite dissolution. Greigite may generally be present as an intermediate stage in the generation of pyrite in the Leg 130 holes; pyrite is first noted in many holes within the initial plateau of high NRM intensity. Below the IRE, high coercivity, noisy AF demagnetization behavior, and unstable thermal demagnetization indicate that greigite dominates the remanence until NRM recovers in the Miocene part of the sequence. Demagnetizations are noisiest, and acquisition of drilling remanence most intense, at the sites where water depth is least (Sites 805, 806, and 807 ), indicating a greater production of greigite, and perhaps lesser survival of magnetite, under these more reduced conditions.
Linear, low-inclination demagnetization segments in samples within this interval may be carried by greigite rather than magnetite; whether these preserve a chemical remanent magnetization (CRM) acquired during diagenesis, or carry a VRM, is not clear.

The increase in intensity and return of interpretable demagnetization paths, which occurs at each site in the Miocene sequence, probably marks an increase in the magnetite content. The AF demagnetization of samples from the Miocene and Oligocene sequence of Sites 803 and 804 appears to indicate the presence of two phases with differing coercivity spectra-presumably magnetite and greigite.

Thermal demagnetization of the lower Miocene and Oligocene chalks is also consistent with the presence of greigite, as the bearer of thermally soft components removed by decomposition by $300^{\circ} \mathrm{C}$, 

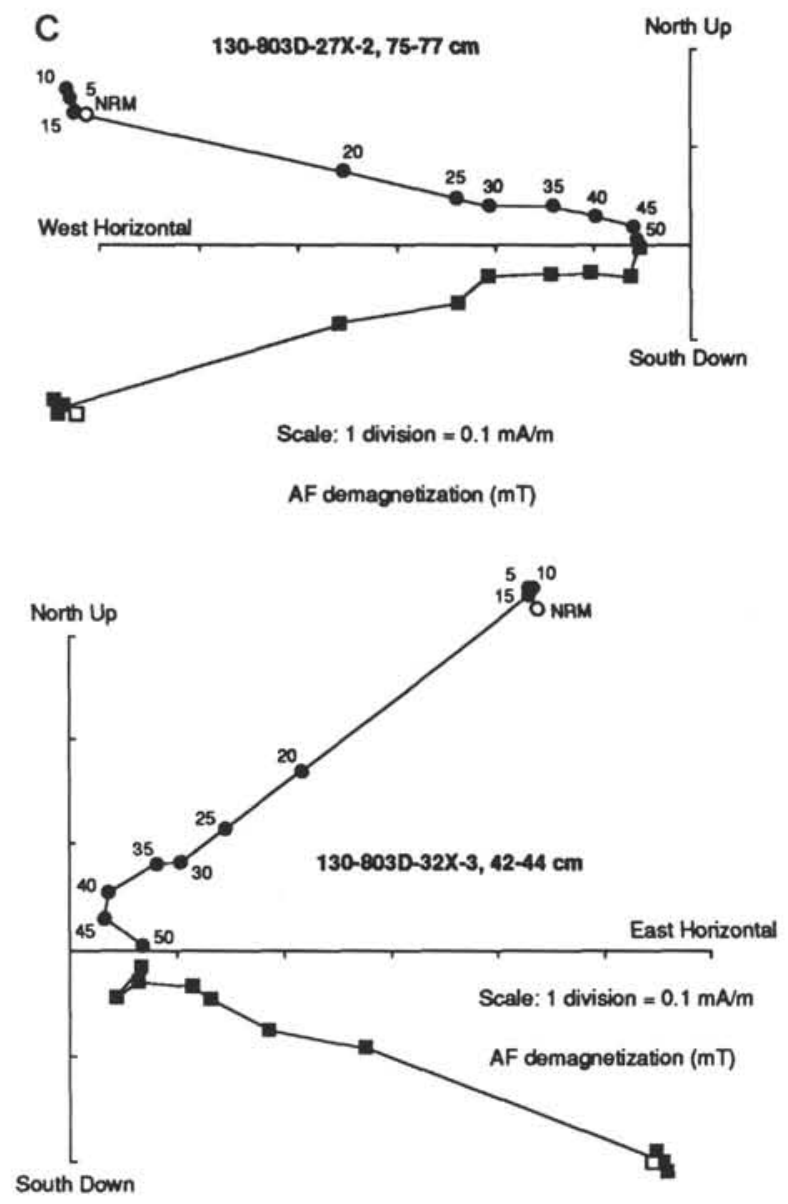

Figure 10 (continued).

and as the precursor of magnetite and hematite as alteration products above $400^{\circ} \mathrm{C}$. Magnetite, which produces the linear demagnetization path through to $575^{\circ}-600^{\circ} \mathrm{C}$ on which the greigite behavior is superimposed, has become the dominant magnetic carrier again in this part of the sequence. Site 806 , with the highest organic input, again shows evidence of the highest greigite:magnetite ratio as its chalks have the noisiest thermal demagnetization.

The implication that significant quantities of magnetite are present in the middle Miocene and Oligocene sequence suggests that magnetite dissolution at these times was less severe than for times since the late Miocene. A less severe reduction, in turn, implies a lower organic input at these times.

Remanence intensity remains relatively high in the deep-water Site 803 from the lower Miocene through to the base of the Eocene, and both the PCM results and the demagnetization behavior of discrete samples indicate the presence of a stable magnetization. Both features suggest that significant quantities of magnetite survive throughout this part of the sequence at Site 803 . Site 807 displays a more complex sequence of alternating high and low intensity from the middle Miocene to the upper Oligocene, implying varying magnetite content. Throughout the lower Oligocene and Eocene are a series of short intervals of higher intensity and more stable magnetization, commonly represented by single samples, again apparently implying increased magnetite content in an otherwise strongly reduced setting. Relatively higher organic input at the shallower water depth of Site 807 may have left sediments there close to the critical redox conditions at which severe magnetite dissolution occurs, making the magnetization at this site a sensitive indicator of short-term changes in organic productivity over the Paleogene.

Incomplete removal of remanence at demagnetization temperatures beyond the Curie point of end-member magnetite in some of the chalks from Sites 803 and 807 suggests the presence of hematite, which has a Curie point at $680^{\circ} \mathrm{C}$ (McElhinny, 1973). Although hematite may be generated as an alteration product during thermal demagnetization (Tarling, 1983), the systematic demagnetization seen in some samples suggests that, in these cases at least, hematite was present before thermal treatment. The presence of hematite and greigite in the same sample is improbable, given their widely different oxidation states. Hematite is equally unlikely to be associated with pyrite. Pyrite is reported throughout most of the carbonate sequence at each site, but significantly is missing from cores from which hematite-bearing samples were taken. Hematite in these samples was probably either introduced detritally or formed by oxidation of magnetite in the upper, relatively oxygenated part of the sediment column. In either case, the survival of hematite indicates that these samples represent the least reducing conditions seen within the carbonate sequence. Hematite appears in the Eocene sequence at Site 803, when this site was at mid-tropical latitudes and organic productivity would have been at a minimum. Hematite also appears in the upper Oligocene sequence in Zone NP25 in Hole $807 \mathrm{~A}$, near prominent ash layers, and may also be present at a slightly older level in Hole 803D, in Zone NP23. Ash input may have increased iron oxide content during this period, outstripping the supply of organic material and so leaving the iron relatively oxidized.

Principal component analysis was applied to samples with stable demagnetization from Sites 803 and 807 . Generally speaking, the highest coercivity or most thermally stable, linear demagnetization segment was fitted. Over the interval in the lower Oligocene and Eocene sequence of Hole $807 \mathrm{C}$, where two populations of inclinations are present, the set of samples with near-zero inclination was excluded. After the conversion of inclinations to absolute paleolatitudes, and application of a five-point running filter, this simple approach yielded the paleolatitude curves seen in Figure 22. Paleolatitude curves for the Pacific Plate generated from averages of hotspot data summarized in Sager (1983) are included in the figure for comparison.

Aliasing of part of the distribution of paleolatitudes around low mean values will have occurred because of the lack of declination as an independent measure of polarity, forcing the calculated means of low paleolatitude higher than their true mean (McFadden and Reid, 1982). This may explain the higher than expected paleolatitudes in the upper $200 \mathrm{~m}$ of Hole $803 \mathrm{D}$, but they could also reflect the susceptibility to overprinting of the weakly magnetized, greigite-dominated magnetic mineralogy over this interval. Lower than expected paleolatitudes from 200 to about 450 mbsf in Hole 803D suggest that a VRM forms the most stable component over this interval. The lack of a primary magnetization in samples from this interval is consistent with partial dissolution of magnetite under intermediate redox conditions, preferentially removing the smaller, higher coercivity, single-domain grains. Fitted inclinations in Hole 803D increase in the lower Oligocene sequence below 450 mbsf to yield appropriate paleolatitudes for the Pacific Plate, implying that primary magnetizations have been preserved. This implies the survival of primary single-domain magnetite, which presumably reflects less reducing conditions at that time. The presence of hematite in the deepest parts of the carbonate sequence implies still less reducing conditions in the Eocene.

A similar pattern applies to Site 807 , although the upper Miocene low-intensity interval is more sparsely represented than at Site 803 because of its more reduced, noisier signal. Additional low-inclination intervals in the lower Miocene-uppermost Oligocene sequence between about 500 and 600 mbsf represent periods of intermediate reduction in which magnetite is partially dissolved as at Site 803 . Similar partial dissolution of magnetite characterizes parts of the Oligocene to Eocene interval below $600 \mathrm{mbsf}$, resulting in the set of samples with inclination near zero. It is worth noting that this equals the current inclination at Site 807, which lies very near the current magnetic equator, rather than the average dipole inclination at this site for the Brunhes Chron. Surviving multidomain magnetites in these samples evidently realign their magnetization rapidly enough to pre- 

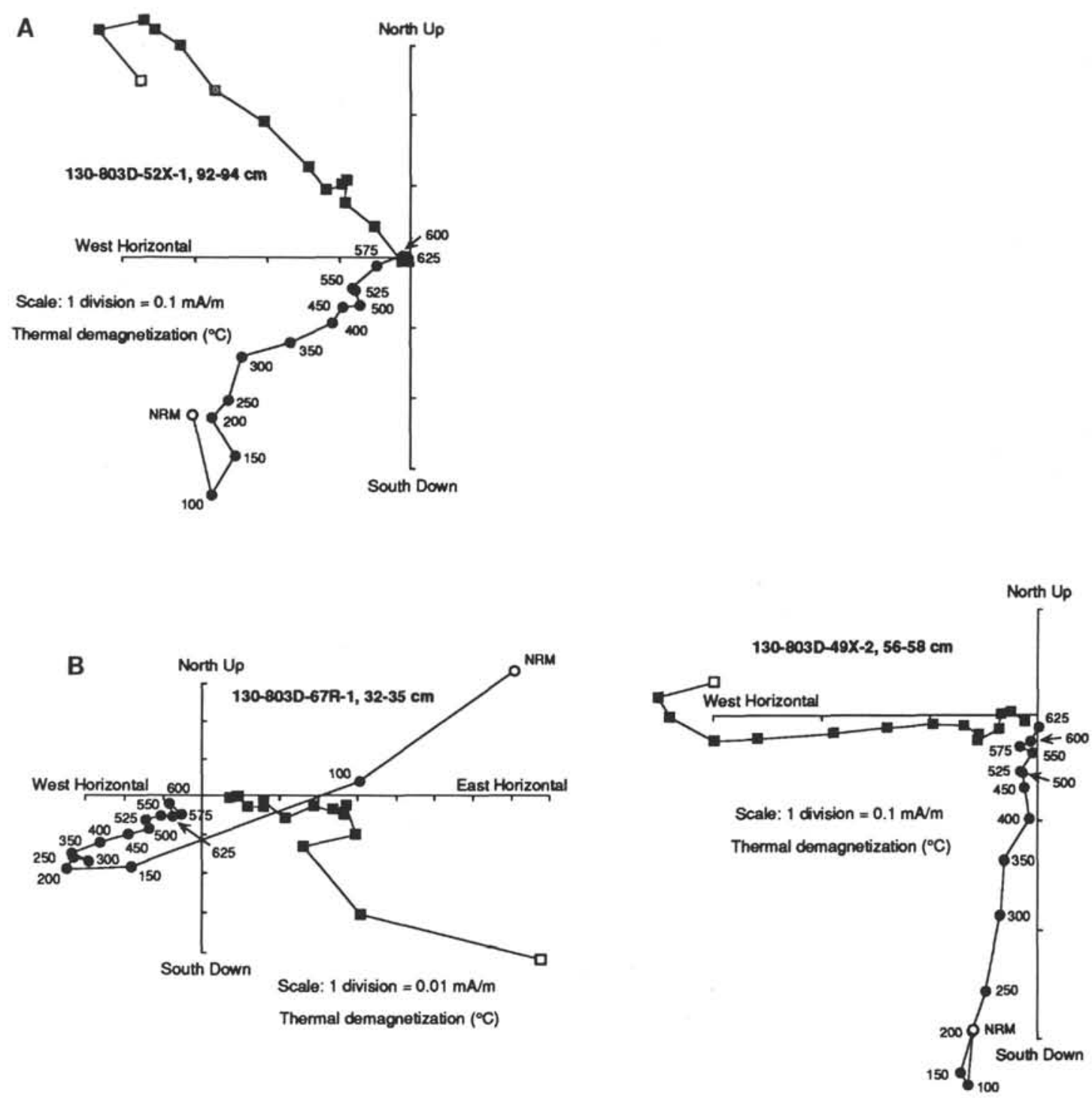

Figure 11. Cartesian plots of thermal demagnetization of chalk and limestone samples from Site 803 below $420 \mathrm{mbsf}$. A. Sample 130-803D-52X-1, 92-94 cm. B. Samples 130-803D-67R-1, 32-35 cm, and -49X-2, 56-58 cm, showing systematic demagnetization continuing above the magnetite Curie point. Thermal steps in degrees Celsius. Symbols as for Figure 10.

serve the secular variation. Other samples scattered through the lower Oligocene to Eocene sequence faithfully record the paleoinclination, indicating that conditions over this interval periodically became less reducing, allowing the survival of single-domain magnetite.

Although some intervals at Site 807 preserve paleolatitude information, many are clearly overprinted, and this pattern persists throughout the carbonate sequence. It is no surprise, then, that AF demagnetization of carbonates at the even shallower Site 289 failed to accurately reveal paleolatitudes.

\section{CONCLUSIONS}

Given the complexity of the mechanism controlling whether primary magnetizations are preserved in Ontong Java carbonate sediments, and the degree to which most of the Leg 130 samples are overprinted, it is reasonable to reject the earlier Leg 30 paleomagnetic paleolatitudes. The agreement between the inclination fitted to the stable magnetization of some of the samples and the Pacific paleolatitude curve is evidence that primary magnetization has been preserved in those samples and, hence. that single-domain magnetite has not been removed by reduction. It also implies that the Ontong Java Plateau has remained part of the Pacific Plate since at least Eocene times.

The pattern of magnetic diagenesis from Leg 130 carbonate sediments reflects the control on iron and sulfate reduction exerted by organic carbon input, over a range near critical values in which magnetite reduction and greigite generation occur. Increased organic input while the sites were near the equatorial zone of upwelling has resulted in nearly complete magnetite dissolution and greigite production. As we progress downhole, reversing the northward drift of Ontong Java with the rest of the Pacific Plate, the magnetic diagenesis of the sediments reflects their origin in progressively less productive mid-tropical waters. As conditions become correspondingly less reduced downhole, multidomain magnetite first reappears in significant quantities, followed by single-domain magnetite. Hematite may be present in the oldest, highest-latitude parts of the carbonate sequence of the deeper water sites, and in intervals where volcanic ash input of iron oxides locally outstrips organically driven reduction.

Redox conditions near the critical level for magnetite dissolution applied at shallow-water Site 807 during the Oligocene and Eocene. The alternating pattern of dissolution and preservation of 


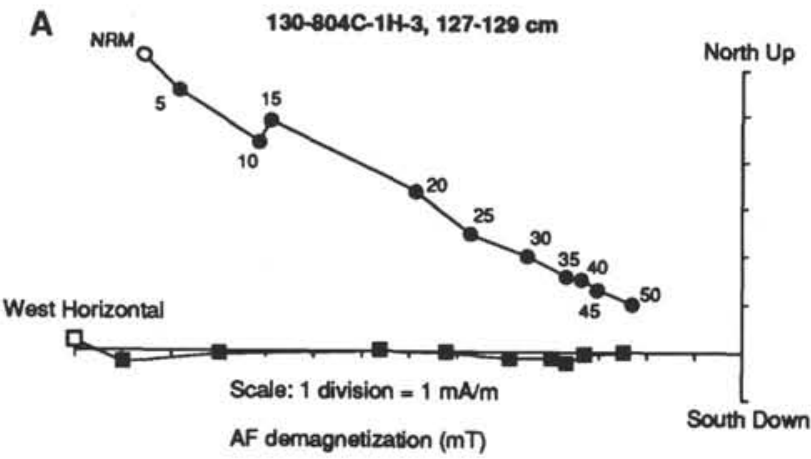

B

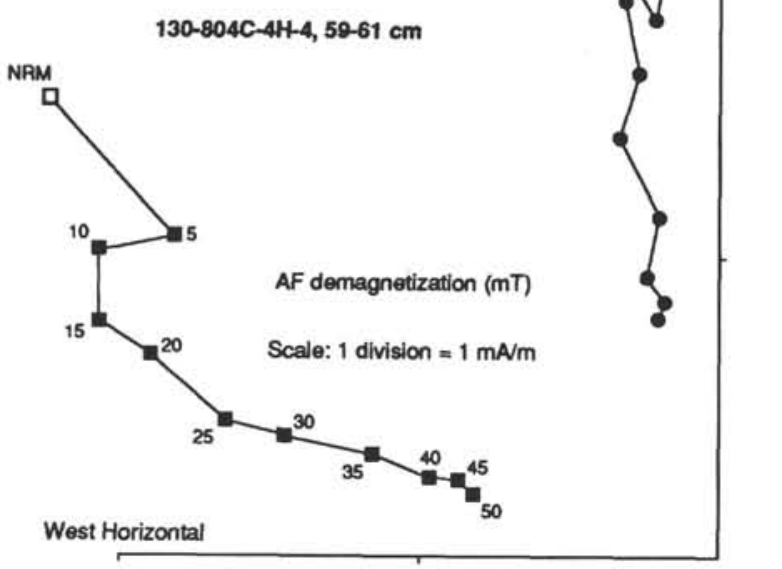

Figure 12. Cartesian demagnetization plots of samples from above the IRE at Site 804. A. Sample 130-804C-1H-3, 127-129 cm. B. Sample 130-804C-4H-4, $59-61 \mathrm{~cm}$. AF steps in mT. Symbols as for Figure 10.

magnetite seen in samples from this site over this interval may serve as an amplified record of climatic variations in organic supply during the Paleogene.

\section{ACKNOWLEDGMENTS}

We would like to thank Rick Reynolds for his advice on the properties of greigite, and Dave Edwards and Peter Percival for assistance at the Black Mountain Palaeomagnetic Laboratory. Financial support for R.J. Musgrave was provided by a Bureau of Mineral Resources, Geology and Geophysics, Australia Post-Doctoral Fellowship.

\section{REFERENCES}

Anson, G.L., and Kodama, K.P., 1987. Compaction-induced inclination shallowing of the post-depositional remanent magnetization in a synthetic sediment. Geophys. J. R. Astron. Soc., 88:673-692.

Arason, P., and Levi, S., 1990. Models of inclination shallowing during sediment compaction. J. Geophys. Res., 95:4481-4500.

Banerjee, S.K., and O'Reilly, W., 1967. The behavior of ferrous ions in iron-titanium spinels. J. Phys. Chem. Solids, 28:1323-1335.

Barton, C.E., and Bloemendal, J., 1986. Paleomagnetism of sediments collected during Leg 90, southwest Pacific. In Kennett, J.P., von der Borch, C.C., et al., Init. Repts. DSDP, 90: Washington (U.S. Govt. Printing Office), 1273-1316.
Berner, R.A., 1967. Thermodynamic stability of sedimentary iron sulphides. Am. J. Sci., 265:777-785.

Bleil, U., 1989. Magnetostratigraphy of Neogene and Quaternary sediment series from the Norwegian Sea: Ocean Drilling Program, Leg 104. In Eldholm, O., Thiede, J., Taylor, E., et al., Proc. ODP, Sci. Results, 104: College Station, TX (Ocean Drilling Program), 829-901.

Bloemendal, J., King, J.W., Tauxe., L., and Valet, J.-P., 1989. Rock-magnetic stratigraphy of Leg 108 Sites $658,659,661$, and 665, eastern tropical Atlantic. In Ruddiman, W., Sarnthein, M., et al., Proc. ODP, Sci. Results, 108: College Station, TX (Ocean Drilling Program), 415-428.

Deamer, G.A., and Kodama, K.P., 1990. Compaction-induced inclination shallowing in synthetic and natural clay-rich sediments. J. Geophys. Res., 95:4511-4530.

Delaney, M.L., and Shipboard Scientific Party, 1991. Inorganic geochemistry summary. In Kroenke, L.W., Berger, W.H., Janecek, T.R., et al.,Proc. ODP, Init. Repts., 130: College Station, TX (Ocean Drilling Program), 549-551.

Duncan, R.A., 1981. Hotspots in the southern oceans-an absolute frame of reference for motion of the Gondwana continents. Tectonophysics, $74: 29-42$.

Espitalié, J., Laporte, J.L., Madec, M., Marquis, F., Leplat, P., Paulet, J., and Boutfeu, A., 1977. Method rapide de caracterisation des roches mère de leur potentiel petrolier et de leur degree d'evolution. Rev. Inst. Fr. Pet., 32:23-42.

Gordon, R. G., 1983. Late Cretaceous apparent polar wander of the Pacific plate: evidence for a rapid shift of the Pacific hotspots with respect to the spin axis. Geophys. Res. Lett., 10:709-712.

Hall, S.A., and Sager, W.W., 1990. Paleomagnetic and rock magnetic properties of sediment samples from Ocean Drilling Program Leg 116, central Indian Ocean. In Cochran, J.R., Stow, D.A.V., et al., Proc. ODP, Sci. Results, 116: College Station, TX (Ocean Drilling Program), 337-344.

Hammond, S.R., Kroenke, L.W., and Theyer, F., 1975. Northward motion of the Ontong-Java Plateau between -110 and -30 m.y.: a paleomagnetic investigation of DSDP Site 289. In Andrews, J.E., Packham, G., et al., Init. Repts. DSDP, 30: Washington (U.S Govt. Printing Office), 415-418.

Hounslow, M.W., Bootes, P.A., and Whyman, G., 1990. Remanent magnetization of sediments undergoing deformation in the Barbados accretionary prism: ODP Leg 110. In Moore, J.C., Mascle, A., et al., Proc. ODP, Sci. Results, 110: College Station, TX (Ocean Drilling Program), 379-391.

Ishikawa, Y., 1967. Magnetic properties of a single crystal of $\mathrm{Fe}_{2} \mathrm{TiO}_{4}$. Phys. Lett., Ser. A, 24:725-727.

Kalcheva, V., Nozharov, P., Kovacheva, M., and Shopov, V. 1990. Paleomagnetic research on Black Sea Quaternary sediments. Phys. Earth Planet. Inter., 63:113-120.

Karlin, R., and Levi, S., 1983. Diagenesis of magnetic minerals in Recent hemipelagic sediments. Nature, 303:327-330.

, 1985. Geochemical and sedimentological control of the magnetic properties of hemipelagic sediments. J. Geophys. Res., 90:10,373-10,392.

Karlin, R., Lyle, M., and Ross Heath, G., 1987. Authigenic magnetite formation in suboxic marine sediments. Nature, 326:490-493.

Kirschvink, J.L., 1980. The least-squares line and plane and the analysis of paleomagnetic data. Geophys. J. R. Astron. Soc., 62:699-718.

Kligfield, R., and Channell, J.E.T., 1981. Widespread remagnetization of Helvetic limestones. J. Geophys. Res., 86:1888-1900.

Kobayashi, K., and Nomura, M., 1972. Iron sulfides in the sediment cores from the Sea of Japan and their geophysical implications. Earth Planet. Sci. Lett., 16:200-208.

Krs, M., Krsová, M., Pruner, P., Zeman, A., Novák, F., and Jansa, J., 1990. A petromagnetic study of Miocene rocks bearing micro-organic material and the magnetic mineral greigite (Sokolov and Cheb basins, Czechoslovakia). Phys. Earth Planet. Inter., 63:98-112.

Levi, S., and Banerjee, S., 1990. On the origin of inclination shallowing in redeposited sediments. J. Geophys. Res., 95:4383-4390.

Mann, S., Frankel, R.B., and Blakemore, R.P., 1984. Structure, morphology and crystal growth of bacterial magnetite. Nature, 310:405-407.

Mannheim, F.T., and Sayles, F.L., 1974. Composition and origin of interstitial waters of marine sediments based on deep sea drill cores. In Goldberg, E.D. (Ed.), The Sea (Vol. 5): Marine Chemistry: New York (Wiley-Interscience), 527-568.

McElhinny, M.W., 1973. Palaeomagnetism and Plate Tectonics: Cambridge (Cambridge Univ. Press).

McFadden, P.L., and Reid, A.B., 1982. Analysis of paleomagnetic inclination data. Geophys. J. R. Astron. Soc., 69:307-319. 
Reynolds, R.L., Fishman, N.S., Wanty, R.B., and Goldhaber, M.B., 1990. Iron sulfide minerals at Cement oil field, Oklahoma: implications for magnetic detection of oil fields, Geol, Soc. Am. Bull., 102:368-380.

Roy, J.L., and Park, J.K., 1974. The magnetization processes of certain red beds: vector analysis of chemical and thermal results. Can. J. Earth Sci., 11:437-471.

Sager, W.W., 1983. A late Eocene paleomagnetic pole for the Pacific Plate Earth Planet. Sci. Lett., 63:408-442.

1988. Paleomagnetism of Ocean Drilling Program Leg 101 sedi ments: magnetostratigraphy, magnetic diagenesis, and paleolatitudes. In Austin, J.A., Schlager, W., et al., Proc. ODP, Sci. Results, 101: College Station, TX (Ocean Drilling Program), 327-360.

Sager, W.W., and Pringle, M.S., 1988. Mid-Cretaceous to early Tertiary apparent polar wander path of the Pacific Plate. J. Geophys. Res. 93:11753-11771.

Schoonen, M.A.A., and Barnes, H.L., 1991a. Reactions forming pyrite and marcasite from solution. I: Nucleation of $\mathrm{FeS}_{2}$ below $100^{\circ} \mathrm{C}$. Geochim. Cosmochim. Acta, 55:1495-1504.

, 1991b. Reactions forming pyrite and marcasite from solution: II. Via FeS precursors below $100^{\circ} \mathrm{C}$. Geochim. Cosmochim. Acta, 55:1505-1514.

Shipboard Scientific Party, 1991. Site 804. In Kroenke, L.W., Berger, W.H., Janecek, T.R., et al., Proc. ODP, Init. Repts., 130: College Station, TX (Ocean Drilling Program), 177-222.
Snowball, I.F., and Thomson, R., 1988. An occurrence of greigite in the sediments of Loch Lomond. J. Quat. Sci., 4:121-125.

1990. A stable chemical remanence in Holocene sediments. $J$. Geophys. Res., 95:4471-4479.

Tarduno, J.A., 1990. Absolute inclination values from deep sea sediments: a reexamination of the Cretaceous Pacific record. Geophys. Res. Lett., 17:101-104.

Tarling, D.H., 1983. Palaeomagnetism: Principles and Applications in Geology, Geophysics and Archaeology: London (Chapman and Hall).

Tauxe, L., Valet, J.-P., and Bloemendal, J., 1989. Magnetostratigraphy of Leg 108 advanced hydraulic piston cores. In Ruddiman, W., Sarnthein, M., et al., Proc. ODP, Sci. Results, 108: College Station, TX (Ocean Drilling Program), 429-439.

van Vreumingen, M.J., 1984. A paleomagnetic and rock-magnetic study of sediment cores from the Zaire submarine fan. Neth. J. Sea Res., 17:342-363.

Zijderveld, J.D.A., 1967. A.C. demagnetization of rocks: analysis of results. In Collinson, D.W., Creer, K.M., and Runcorn, S.K. (Eds.), Methods in Palaeomagnetism: Amsterdam (Elsevier), 368-371.

Date of initial receipt: 5 September 1991

Date of acceptance: 17 June 1992

Ms 130B-035 

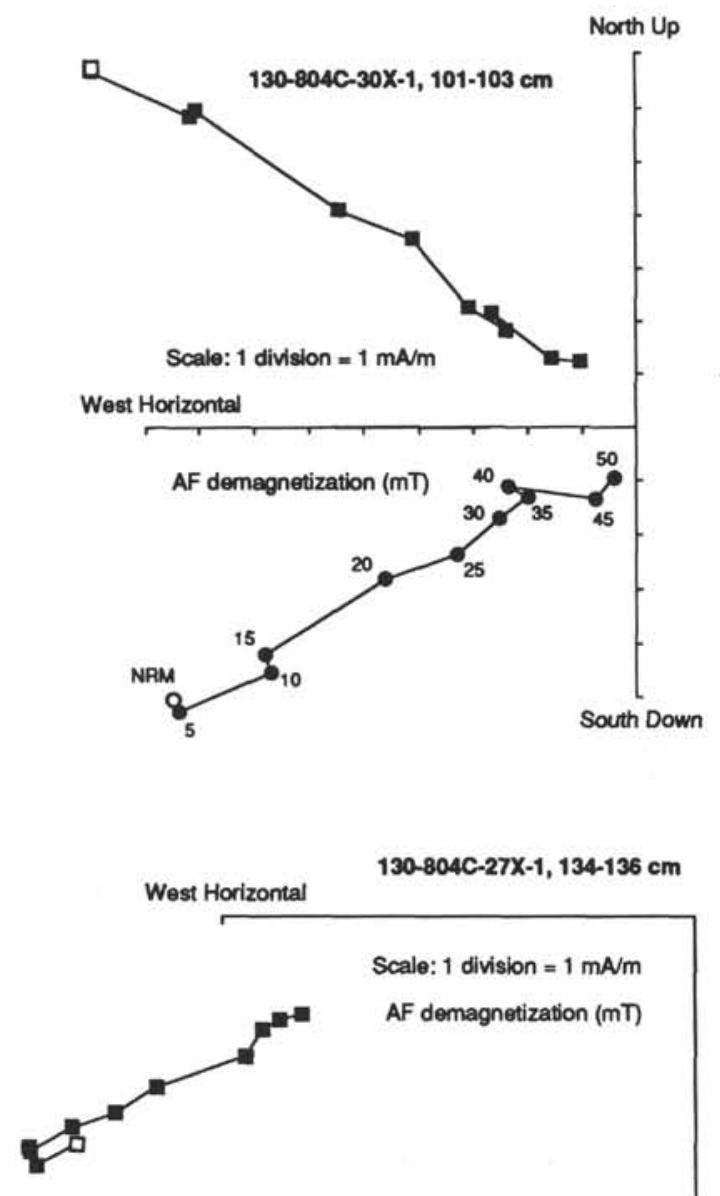

$130-804 C-27 X-1,134-136 \mathrm{~cm}$

Scale: 1 division $=1 \mathrm{~mA} / \mathrm{m}$

AF demagnetization ( $\mathrm{mT}$ )

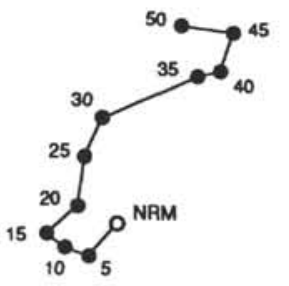

Figure 13. Cartesian demagnetization plots of samples from below $110 \mathrm{mbsf}$ at Site 804, where NRM intensities increase again. A. Sample 130-804C-30X-1, 101-103 cm. B. Sample 130-804C-27X-1, 134-136 cm. AF steps in mT. Symbols as for Figure 10.
$130-806 \mathrm{~B}-38 \times-2,97-99 \mathrm{~cm}$

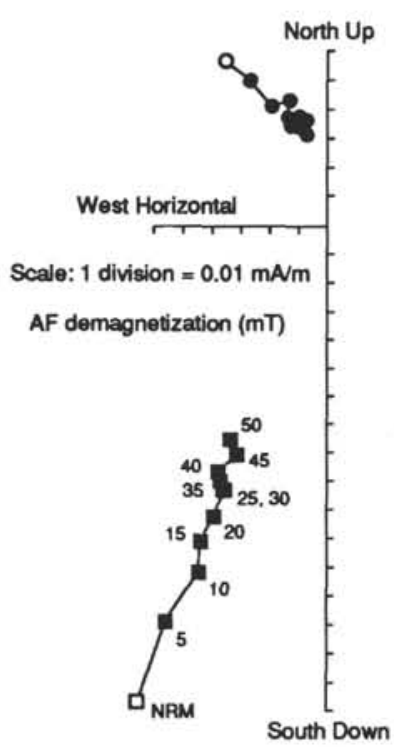

Figure 14. Cartesian demagnetization plot of Sample 130-806B-38X-2, 97-99 $\mathrm{cm}$. A steeply inclined component is carried by a high-coercivity phase, which is not demagnetized at $50 \mathrm{mT}$. AF steps in mT. Symbols as for Figure 10. 

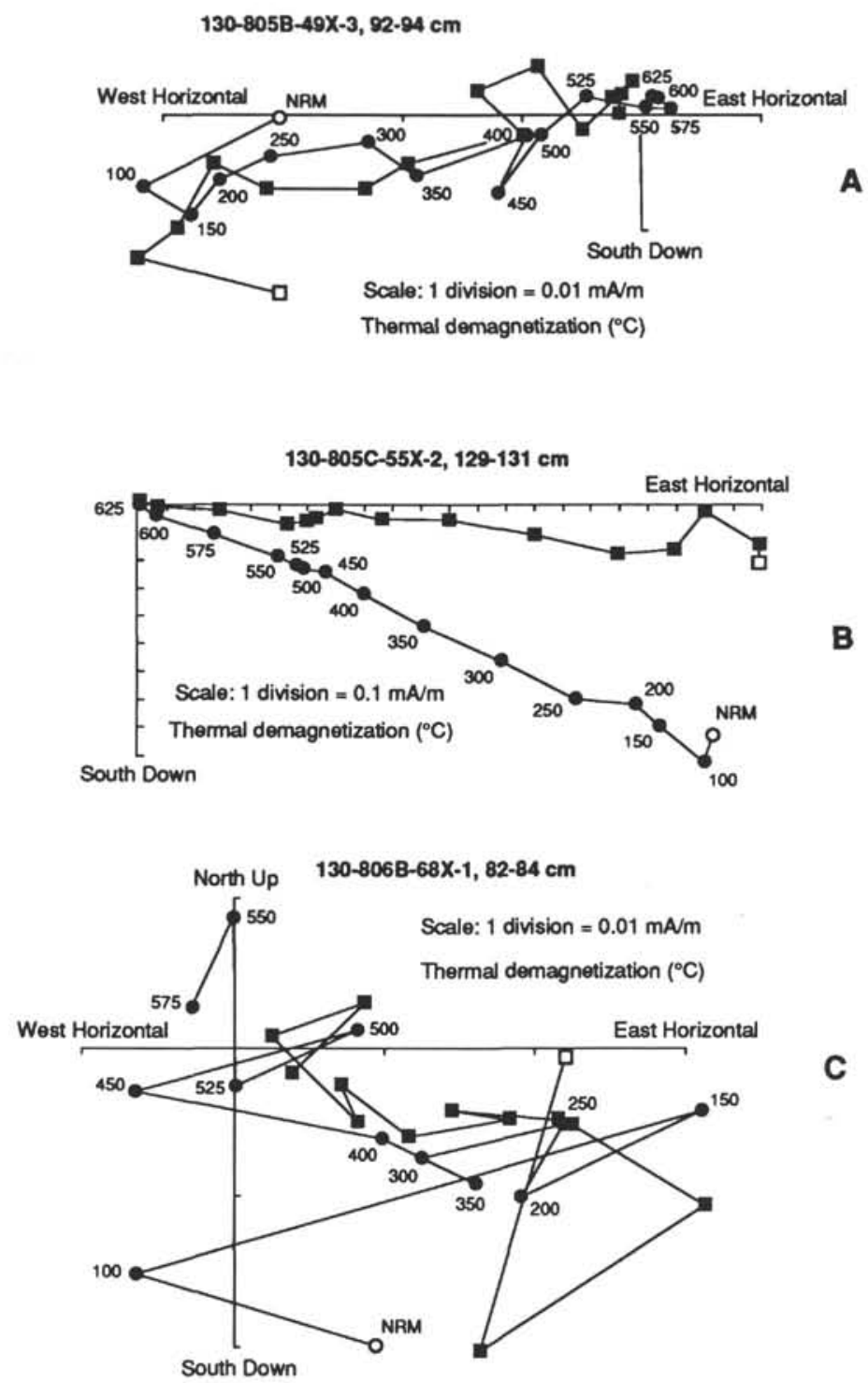

Figure 15. Cartesian plots of thermal demagnetization of chalk samples from Sites 805 and 806. A. Sample 130-805B-49X-3, 92-94 cm. B. Sample 130805C-55X-2, 129-131 cm. C. Sample 130-806B-68X-1, 82-84 cm. Thermal steps in degrees Celsius. Symbols as for Figure 10. 
130-807A-1H-2, 103-105 cm

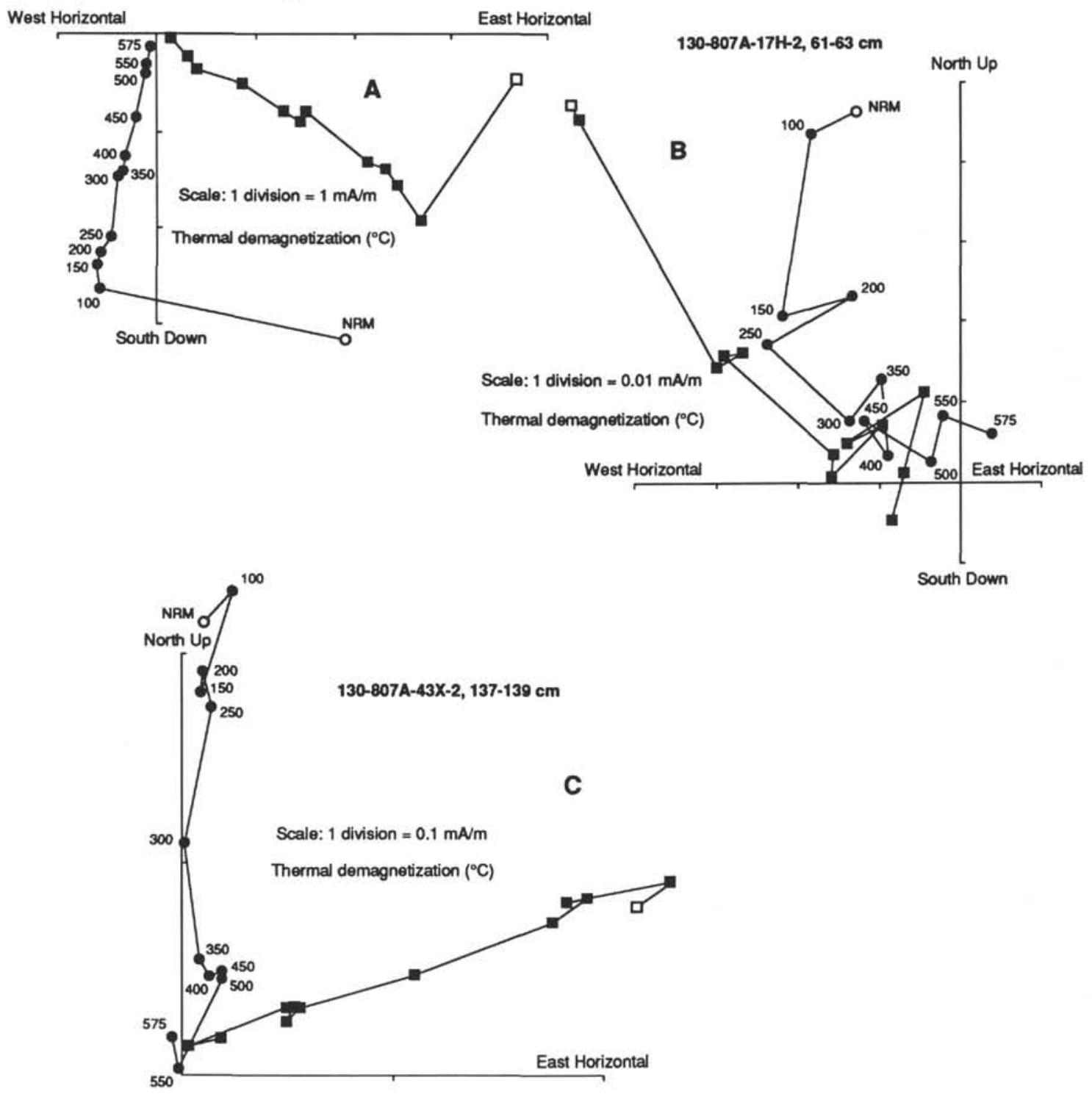

Figure 16. Cartesian plots of thermal demagnetization of dried ooze samples from Hole 807A. A. Sample 130-807A-1H-2, 103-105 $\mathrm{cm}$, from above the IRE. B. Sample 130-807A-17H-2, 61-63 cm, from the weakly magnetized interval below the IRE. C. Sample 130-807A-43X-2, 137-139 cm, from below $390 \mathrm{mbsf}$, where NRM intensity increases again. Thermal steps in degrees Celsius. Symbols as for Figure 10. 


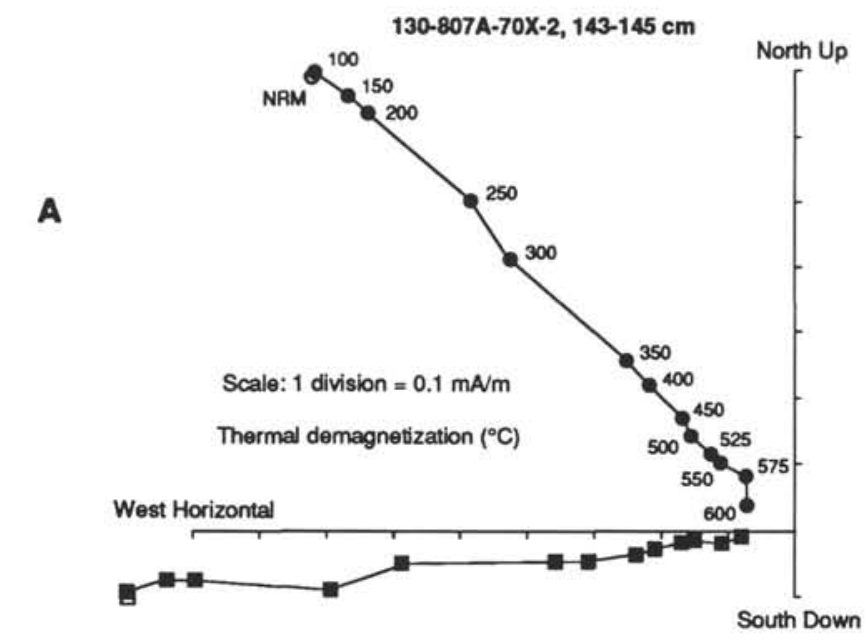

B

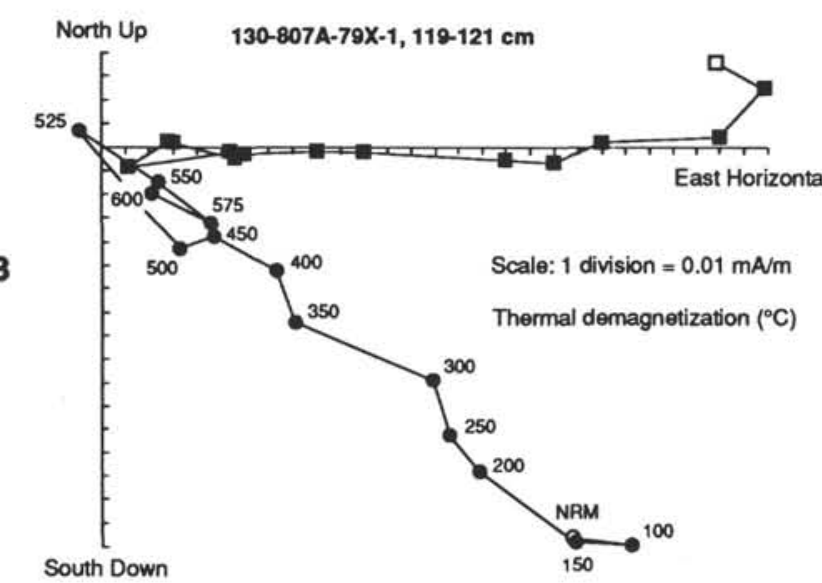

Figure 17. Cartesian plots of thermal demagnetization of chalk samples from Hole 807A. A. Sample 130-807A-70X-2, 143-145 cm, from the interval between 600 and 707 mbsf. B. Sample 130-807A-79X-1, 119-121 cm, from the weakly magnetized, low-inclination interval between $707 \mathrm{mbsf}$ and the bottom of the hole. Thermal steps in degrees Celsius. Symbols as for Figure 10.
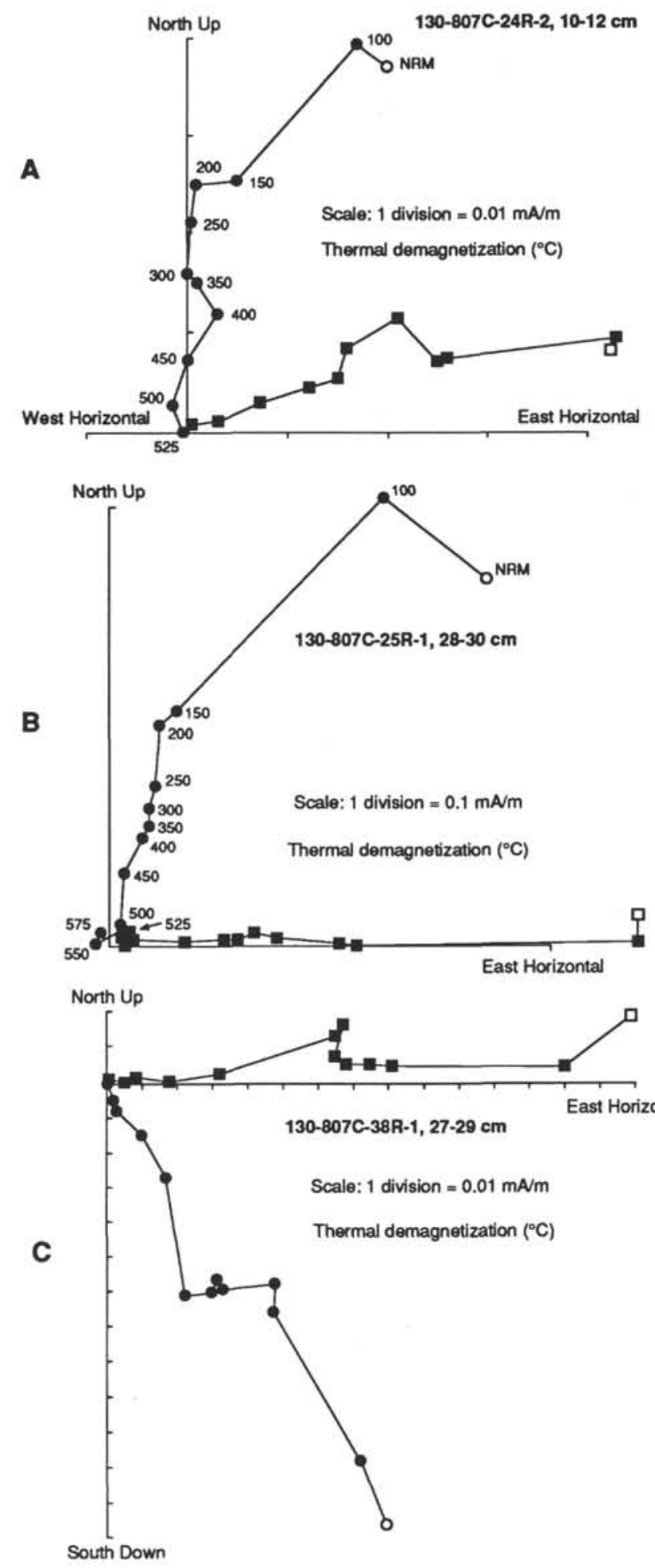

Figure 18. Cartesian plots of thermal demagnetization of chalk and limestone samples from Hole 807C. A. Sample 130-807C-24R-2, 10-12 cm, which demagnetizes toward an inclination of about $-20^{\circ}$. B. Sample 130-807C-25R-1, $28-30 \mathrm{~cm}$, which demagnetizes toward the horizontal. C. Sample 130-807C$38 \mathrm{R}-1,27-29 \mathrm{~cm}$, which includes a demagnetization segment with an inclination of about $-20^{\circ}$ between two horizontal segments. Thermal steps in degrees Celsius. Symbols as for Figure 10. 
130-803D-4H-2, $75-77 \mathrm{~cm}$

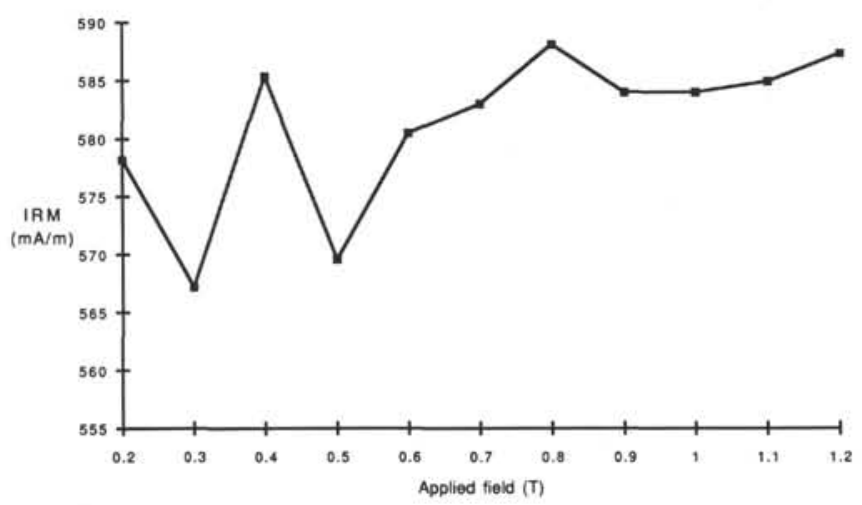

$130-8030-30 X-2,38-40 \mathrm{~cm}$

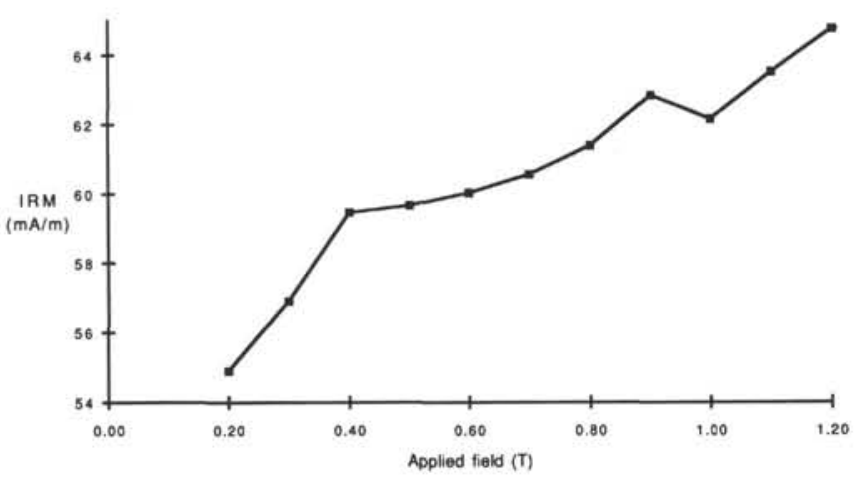

130-803D-6H-3, $74-76 \mathrm{~cm}$

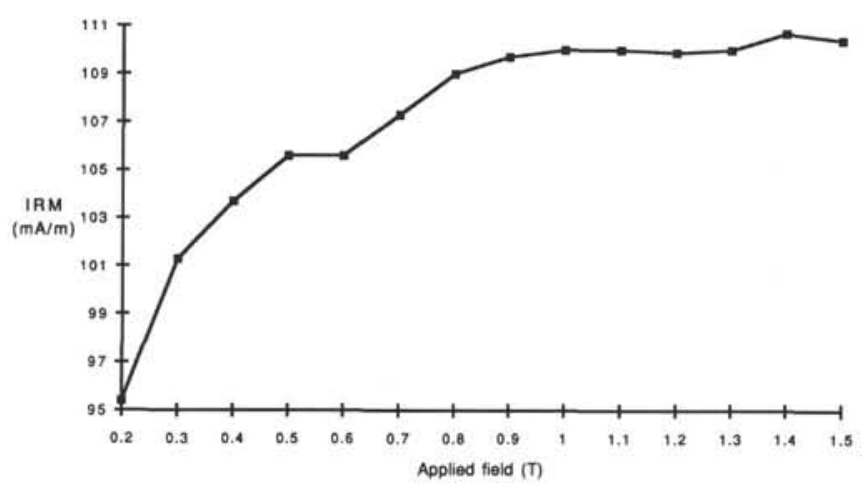

$130-8030-45 X-2,116-118 \mathrm{~cm}$

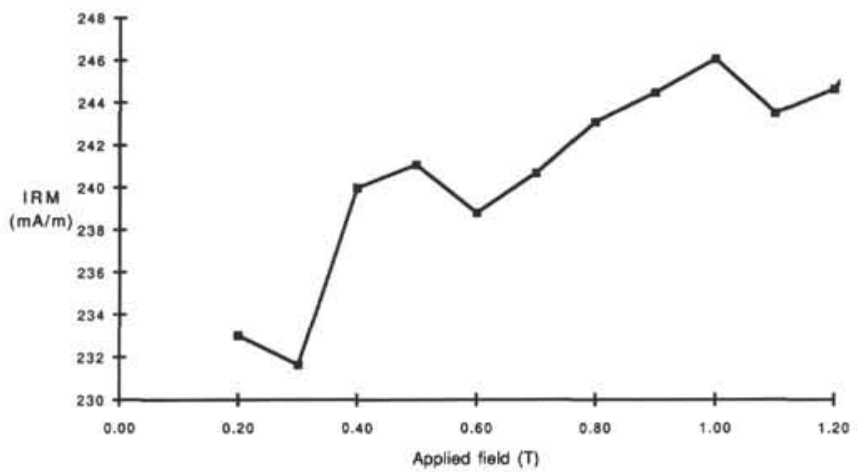

Figure 19. IRM acquisition curves for samples from Hole 803D. Magnetite is saturated by $0.2 \mathrm{~T}$. Sample 130-803D-4H-2, 75-77 cm, lies above the IRE and shows a poorly defined increase in IRM above $0.2 \mathrm{~T}$, which may indicate the presence of a high-coercivity phase; the signal is dominated by noise from the proportionally much larger magnetite IRM. Sample 130-803D-6H-3, 74-76 cm, which lies just below the IRE, shows the largest increase in IRM above $0.2 \mathrm{~T}$ of all the samples studied. Samples 130-803D-30X-2, 38-40 cm, and -45X-2, 116-118 cm, illustrate the continued presence of a high coercivity phase downhole to at least the upper Oligocene.

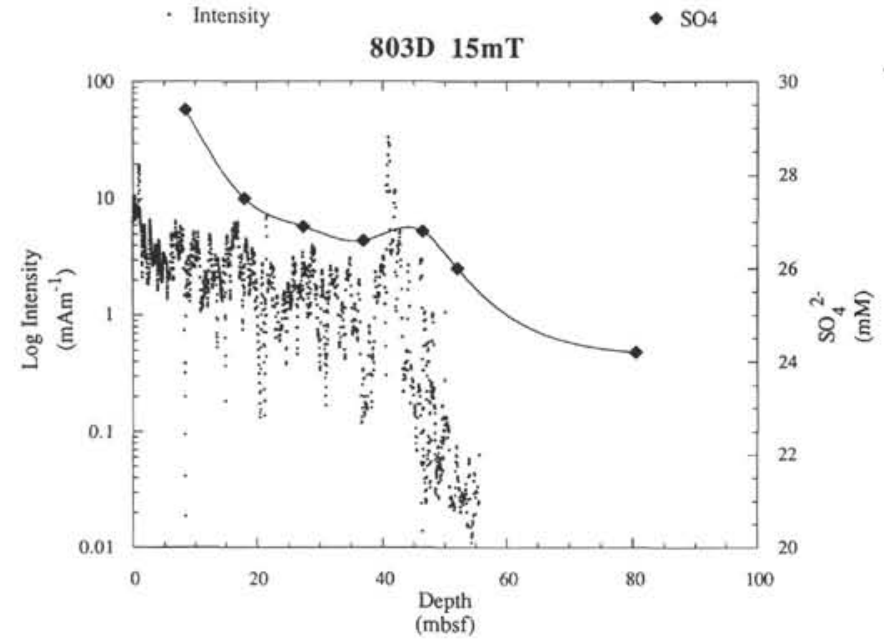

Figure 20. Remanence intensity after 15-mT demagnetization (small dots) and sulfate ion concentration (diamonds, fitted by cubic splines) vs. sub-bottom depth for Holes 803D, 804B, 805C, 806B, and 807A.

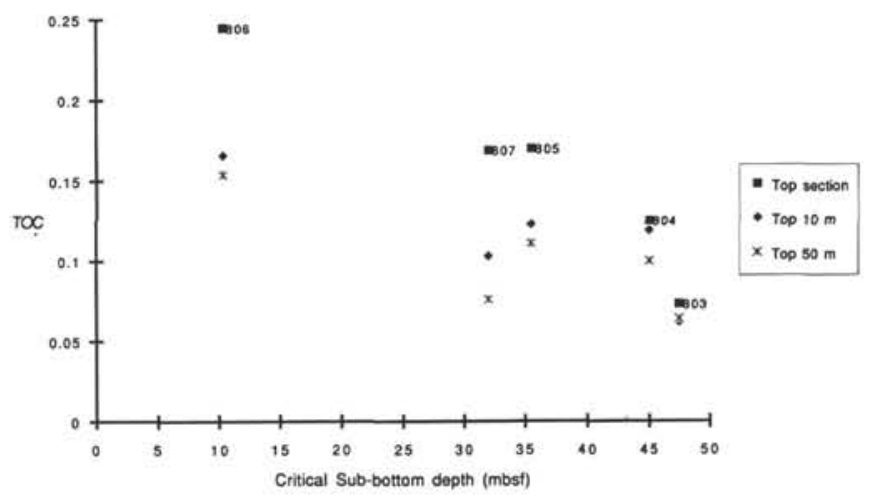

Figure 21. Total organic carbon (TOC) vs. sub-bottom depth of the IRE for each site. TOC is shown for a sample from Section 1 of the top core at each site and as averages over the first $10 \mathrm{mbsf}$ and the first $50 \mathrm{mbsf}$ at each site. 
Paleolatitude (degrees)

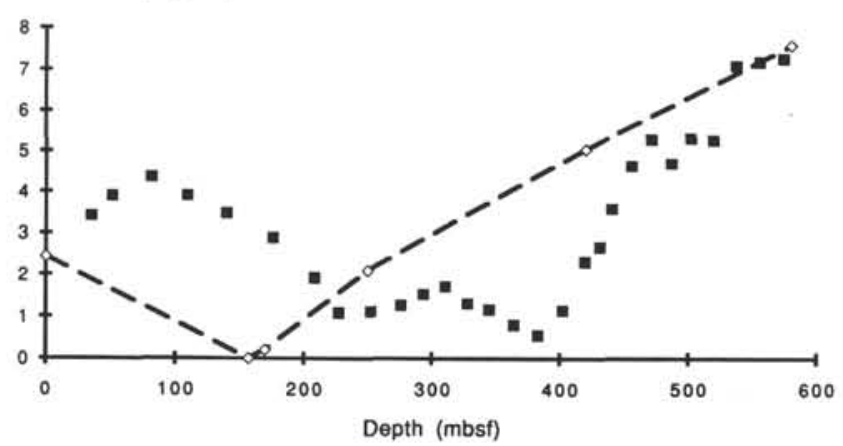

803D

aleolatitude (degrees)
$807 \mathrm{~A}$ and $807 \mathrm{C}$

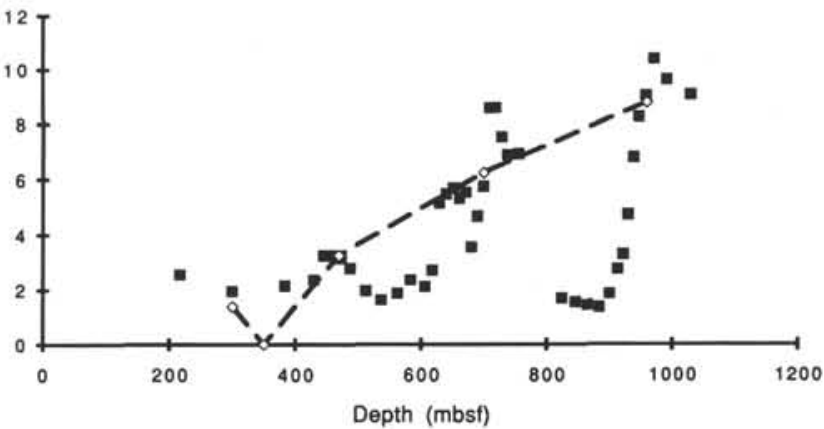

Figure 22. Paleolatitudes from five-point, smoothed, fitted inclinations from Sites 803 and 807 . The dotted line joins calculated paleolatitudes (diamonds) for each site, based on an average of the Pacific Plate hotspot motion poles summarized in Sager (1983). 